This is the final peer-reviewed accepted manuscript of:

Claudio Carletti, Giuseppina Montante, Cataldo De Blasio, Alessandro Paglianti, Liquid mixing dynamics in slurry stirred tanks based on electrical resistance tomography, Chemical Engineering Science, Volume 152, 2016, Pages 478-487, ISSN 0009-2509

The final published version is available online at:

https://doi.org/10.1016/i.ces.2016.06.044

Rights / License:

The terms and conditions for the reuse of this version of the manuscript are specified in the publishing policy. For all terms of use and more information see the publisher's website.

This item was downloaded from IRIS Università di Bologna (https://cris.unibo.it/)

When citing, please refer to the published version. 


\title{
Liquid mixing dynamics in slurry stirred tanks based on electrical resistance tomography
}

\author{
Claudio Carletti ${ }^{\mathrm{a}}$, Giuseppina Montante ${ }^{\mathrm{b}}$, Cataldo De Blasio ${ }^{\mathrm{a}, \mathrm{d}}$, Alessandro Paglianti $^{\mathrm{c}^{*}}$
}

aProcess Design and Systems Engineering Laboratory, Åbo Akademi University, Biskopsgatan 8, FIN-20500 Åbo, Finland.

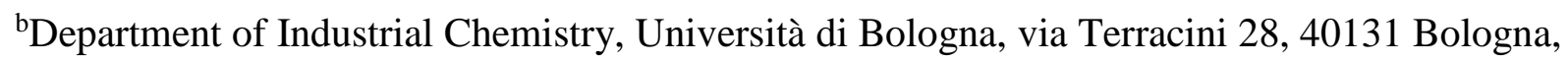
Italy.

${ }^{\mathrm{c}}$ Department of Civil, Chemical, Environmental and Materials Engineering, Università di Bologna, via Terracini 28, 40131 Bologna, Italy.

${ }^{\mathrm{d} E n e r g y ~ E n g i n e e r i n g ~ a n d ~ E n v i r o n m e n t a l ~ P r o t e c t i o n, ~ D e p a r t m e n t ~ o f ~ E n e r g y ~ T e c h n o l o g y, ~}$ Aalto University. Sähkömiehentie 4, 02150 Espoo, Finland.

In this work, liquid mixing in a solid-liquid baffled stirred tank is investigated experimentally by Electrical Resistance Tomography (ERT). Since the technique works non-intrusively in opaque systems, the limitations of the most widespread experimental methods for the mixing time estimations are overcame. Whole-field data on the homogenization dynamics are collected with liquid only and with a mass ratio of suspended solid to liquid equal to 0.43 . The liquid mixing time, which is often adopted as a measure of the intensity of mixing in turbulent stirred tanks, leads to quantitatively assess the significant difference in the scalar mixing process in the agitated slurry with respect to the single-phase systems. Besides, novel definitions for intensity, scale and rate of change of mixing are proposed. With respect to the conventional mixing time estimation, the parameters extracted from the raw ERT data provide a deeper insight into the evaluation of the scalar mixing dynamics in stirred tanks.

Keywords: Mixing time; Slurries; Tomography; Intensity and Scale of Segregation; Opaque Systems; Stirred tank.

* To whom correspondence should be addressed. Tel.: +39051 2090403 Fax: +39 051

6347788. E-mail address: alessandro.paglianti@unibo.it 


\section{Introduction}

Stirred tanks and several other industrial equipment (such as fluidized beds and slurry bubble columns, just to mention a couple of examples) are widely adopted in industrial processes for tackling multiphase systems at high dispersed phase loadings and under turbulent flow regime, either for physical operations and for (bio-)chemical reactions. The development of experimental methods for their characterization has experienced significant advancements in the past decade (Dudukovic, 2002; Stanley and Bolton, 2008), but several aspects of the complex interactions governing the interphase transfer of momentum, the effect of the dispersed phase on the turbulent field of the continuous phase, the particle-particle interactions still require extensive investigation (Balachandar and Eaton, 2010). When dealing with solid-liquid mixing, the solid suspension and the transport of species through the liquid are the main features of interest (Ayranci et al., 2013). In this work, the latter aspect is addressed, by experiments on the overall time and the dynamic behaviour for the achievement of a defined level of liquid mixedness in dense suspensions. Electrical Resistance Tomography (ERT) is selected as the investigation tool.

The applicability of ERT to dense particulate systems has been already demonstrated in a number of works (Sharifi and Young, 2013), moving from preliminary qualitative investigations based on the visual observation of the measured conductivity to, more recently, the quantitative analysis of different variables, among which the concentration distribution of the dispersed phase is the most widely explored. Examples of application of ERT to the observation of the homogenization dynamics of a tracer via conductivity tomograms have been presented among the first by McKee et al. (1995) and Dickin and Wang (1996) for single-phase stirred tanks. Afterwards, more extensive applications of ERT have been presented for the determination of the mixing time in single-phase Newtonian (Holden et al., 1998; Kim et al., 2006; Rodgers et al., 2011) and non-Newtonian fluids (Pakzad et al., 2013). Also, the dependency of the rate of mixing of miscible liquids on the tracer addition position has been assessed, based either on 2D tomograms and on the 3D reconstruction of the conductivity field (Mann et al., 2001). Moreover, the mixing time has been investigated in gas-liquid systems (Wang et al., 2000; Hamood-ur-Rehman et al., 2012, Montante and Paglianti, 2015; Babaei et al, 2015) and in emulsification processes (Rodgers et al., 2009).

Slurry stirred tanks have been more often investigated by ERT for the assessment of the solid concentration distribution under continuous agitation or transient conditions, (e.g. Stanley and Bolton, 2008; Hosseini et al., 2010; Tahvildarian et al., 2011; Harrison et al., 2012). On the other hand, at the best of our knowledge, ERT data on the liquid homogenization dynamics 
are not available in the open literature for solid-liquid stirred suspensions, except for, very recently, an unbaffled tank stirred by a six-bladed pitched blade turbine pumping downwards (Sardeshpande et al., 2016) for mass ratios of suspended solids to liquid up to 0.125 . The mixing time was estimated from the average conductivity on two horizontal sections of the vessel.

The time required to achieve a fixed level of mixedness in moderately dilute and dense solidliquid baffled stirred tanks has been investigated in a few previous works only, namely Kraume (1992) who adopted a decolorization method, Bujalski et al. (1999), by decolorization and conductivity probes, Micheletti et al. (2003) and Sardeshpande et al. (2009), by conductivity probes. The relationship between the mixing time and the clear liquid layer height has been observed for dense systems (Kraume, 1992; Bujalski et al., 1999). In all cases, dramatic deviations with respect to single-phase stirred tanks have been found in specific conditions, being the mixing time about equal or much longer depending on the impeller speed and on the solid loading.

In this work, ERT is adopted for the characterization of the homogenization dynamics of a tracer in a slurry baffled stirred tank. Besides the classical definition of a global mixing time based on a fixed mixedness level, the local information collected by ERT are exploited deeply to provide more insight into the complexity of the systems under consideration. Following general definitions proposed by Kukukova et al. (2009), a novel route for the analysis of mixing and segregation is suggested.

\section{Material and methods}

A fully baffled stirred tank, whose main characteristics are depicted in Fig. 1, was adopted for the suspensions of glass particles (density, $\rho_{\mathrm{s}}=2500 \mathrm{~kg} / \mathrm{m}^{3}$ ) in a very dilute solution of sodium chloride in demineralised water (salt concentration of $0.5 \mathrm{~g} / \mathrm{L}$ ). It was a flat bottomed Plexiglas cylinder of diameter $\mathrm{T}=0.232 \mathrm{~m}$ and height $\mathrm{H}=0.280 \mathrm{~m}$. Agitation was provided by a single centrally-mounted 6-bladed $45^{\circ}$ Pitched Blade Turbine (PBT) pumping downward of diameter $\mathrm{D}=\mathrm{T} / 3$ and off-bottom clearance $\mathrm{C}=\mathrm{T} / 3$.

The dynamic homogenization of a passive tracer in the stirred tank was assessed by the ITS P2000 instrumentation (Industrial Tomography Systems Ltd).

The measurements consisted in the dynamic estimation of the local conductivity on four horizontal planes before and after the almost instantaneous injection of $2.6 \mathrm{~mL}$ of saturated $\mathrm{NaCl}$ aqueous solution (salt concentration of about $350 \mathrm{~g} / \mathrm{L}$ ) in the solid-liquid suspension of lower conductivity. 
Measurements in liquid only were also carried out for a direct evaluation of the solids effect on the homogenization process. The position of the tracer addition was varied for assessing to what extend it affects mixing, based on previous findings on reacting systems (e.g. Assirelli et al., 2002) and dense solid-liquid systems (Bujalski et al., 1999). Therefore, three positions were selected as depicted in Fig. 1, namely, two close to the liquid free surface, one in the centre (A1) and the other towards the wall between two baffles (A2). The last position was in the centre just below the impeller (A3).

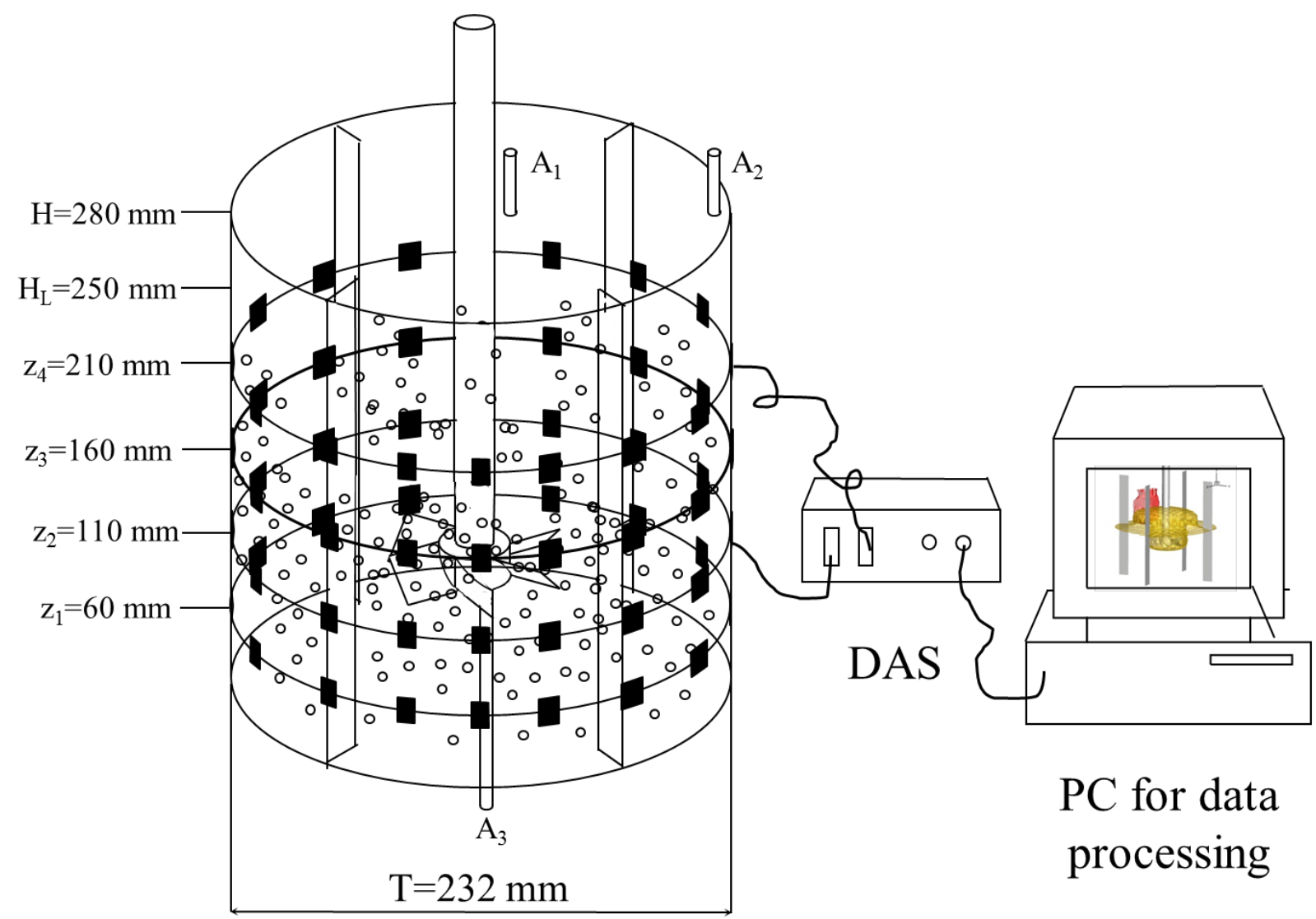

Fig. 1. The stirred vessel and the measurement system.

The investigated conditions are summarized in Tab. 1 together with the "just suspended" impeller speed, NIS. Due to the critical dependency of the suspension mechanisms on the geometrical characteristics (Ayranci et al., 2012), NJs was estimated visually rather than by literature correlations, placing a mirror inclined of $45^{\circ}$ below the vessel base and adopting the well-known Zwietering's criterion.

Tab. 1. Summary of the operating conditions.

\begin{tabular}{l|l|l|l} 
Mean particle size, & $\mathrm{kg}$ solid/kg liquid, & Impeller speed, & Just suspended speed, \\
\hline
\end{tabular}




\begin{tabular}{c|c|c|c}
\hline $\mathrm{dp}[\mu \mathrm{m}]$ & $\mathrm{X}[-]$ & $\mathrm{N}[\mathrm{rpm}]$ & $\mathrm{N}_{\mathrm{JS}}[\mathrm{rpm}]$ \\
\hline 138 & 0.43 & $500 ; 900$ & 580 \\
385 & 0.43 & $500 ; 900$ & 700 \\
\hline Single phase & - & 500,900 & - \\
\hline
\end{tabular}

The vessel wall was equipped with equally spaced squared stainless steel electrodes of $20 \mathrm{~mm}$ side and $1 \mathrm{~mm}$ thickness fixed along four circumferential planes (16 electrodes per plane), located at the dimensionless elevations of $\mathrm{z} / \mathrm{T}=0.26,0.47,0.67,0.90$, that is one below and three above the impeller. The liquid level, $\mathrm{H}_{\mathrm{L}}$, was always kept equal to $0.25 \mathrm{~m}$.

The Data Acquisition System (DAS) and the electrodes were connected by coaxial cables in order to reduce the signal interferences.

The voltage difference was measured by the circular adjacent strategy (Dickin and Wang, 1996); the local conductivity (316 values per plane) was obtained from the voltage measurements by the linearized back projection algorithm (e.g. Hosseini et al., 2010) in real time on a square mesh with each cell of a side of 20 pixels, corresponding to $11.5 \mathrm{~mm}$. The dimensionless conductivity, $\mathrm{C}_{\mathrm{i}}$, was calculated as the conductivity of the slurry during the tracer dispersion divided by the conductivity of the medium before the tracer injection.

The main measurement parameters are summarized in Tab. 2. The amplitude and the frequency of the injected current were optimized by preliminary calibration tests and are close to those previously identified for similar applications (Williams, et al., 1996). For each set of acquisitions, up to 1500 total instantaneous measurements were collected depending on the time required to complete the tracer homogenization, with an acquisition rate of 6.28 frames per second, thus closely following the dynamics of the process. For selected conditions, the measurements were repeated and a good reproducibility of the conductivity tomograms was found. The values of the standard deviation of the local conductivity varied from $14 \%$ to $1.5 \%$ depending on the plane. Higher values were found close to the injection, since the blade passage and the injection time were not synchronized, while much smaller values were obtained far from the injection.

Tab. 2. Main measurement parameters.

\begin{tabular}{cc}
\hline Parameter & Value \\
\hline Number of instantaneous measurements & $600-1500$ \\
Acquisition frequency (frame/s) & 6.28 \\
Amplitude of the injected current $(\mathrm{mA})$ & 15 \\
Frequency of the injected current $(\mathrm{Hz})$ & 9600 \\
Tracer injection position & Top centre, top wall, bottom centre \\
Temperature & constant, $25 \pm 2^{\circ} \mathrm{C}$ \\
\hline
\end{tabular}




\subsection{Homogenization dynamics and mixing time determination}

The classical processing route for the evaluation of the liquid mixedness dynamics is based on the calculation of the time required to reduce the intensity of segregation below a desired value. For batch stirred tanks, the t95 mixing time is most often adopted, which is defined as the time required to reach a level of variation of the tracer's normalized concentration within $\pm 5 \%$ of the final value, corresponding to the complete homogeneity. For single phase flows, different degrees of homogeneity, $x$, can be accounted for by the following relationship suggested by Grenville \& Nienow (2004) for a single impeller:

$t_{x}=t_{95} \frac{\ln (1-x / 100)}{\ln (1-0.95)}$

which is valid under the assumption that the tracer concentration decays exponentially.

In this work, the measured dimensionless conductivity in the cell $\mathrm{i}, \mathrm{C}_{\mathrm{i}}(\mathrm{t})$, is adopted for the estimation of the local tracer homogenization dynamics after a suitable normalization, being it proportional to the tracer concentration. The normalized local conductivity, $\chi_{\mathrm{i}}$, is calculated as:

$\chi_{i}(t)=\frac{C_{i}(t)-C_{i}(0)}{C_{i}(\infty)-C_{i}(0)}$

where $\mathrm{C}_{\mathrm{i}}(0)$ and $\mathrm{C}_{\mathrm{i}}(\infty)$ are the initial (before the tracer addition) and the final (after the complete homogenization) conductivity in the cell i, respectively. As an example, in Fig. 2 the local normalized conductivity, as calculated by Eqn. (2) on the $\mathrm{z}_{4}$ plane at different times after the tracer injection is shown for one selected condition.

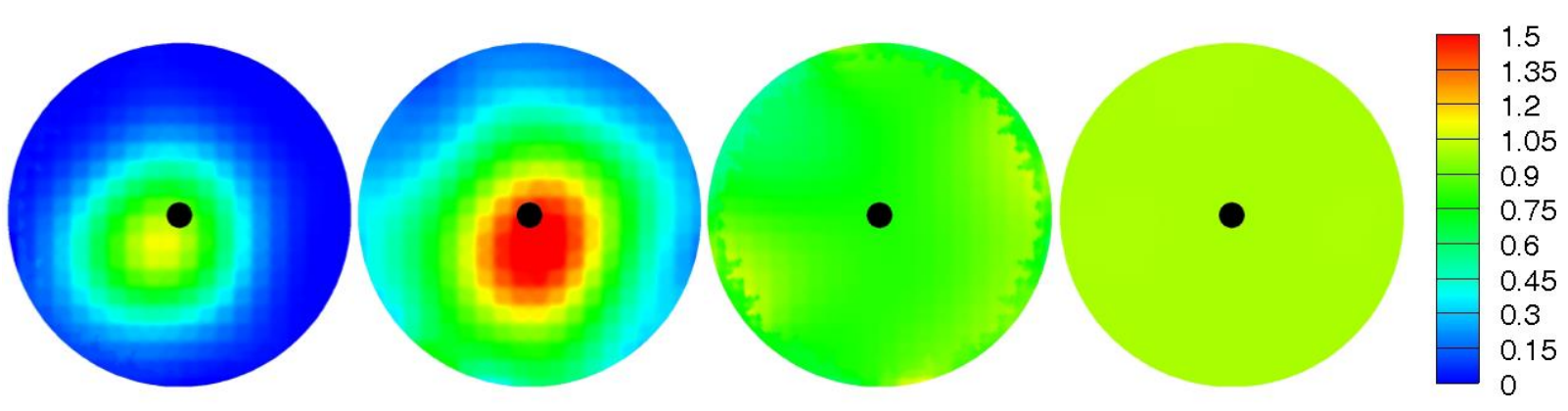


(a)

(c)

(d)

Fig. 2. Tomograms of normalized instantaneous local conductivity $\chi_{i}$ on the $\mathrm{z}_{4}$ plane. $\left(d_{p}=385 \mu m, X=0.43, N=500 r p m\right.$, tracer addition: A1). (a) $t=1 s$; (b) $t=5 s ;$ (c) $t=10 \mathrm{~s}:$ (d) $t=70 \mathrm{~s}$.

The time evolution of the normalized local conductivity averaged over each measurement plane, $\bar{\chi}(t)$ is depicted in Fig. 3(a), together with the lines corresponding to $\pm 5 \%$ of the final normalized conductivity, $\bar{\chi}(\infty)$, for the same sample condition of Fig. 2. For further analysis of the time series, the noise associated with the particles flow is smoothed out, by applying a moving window average over $0.9 \mathrm{~s}$, as shown in Fig. $3 \mathrm{~b}$.
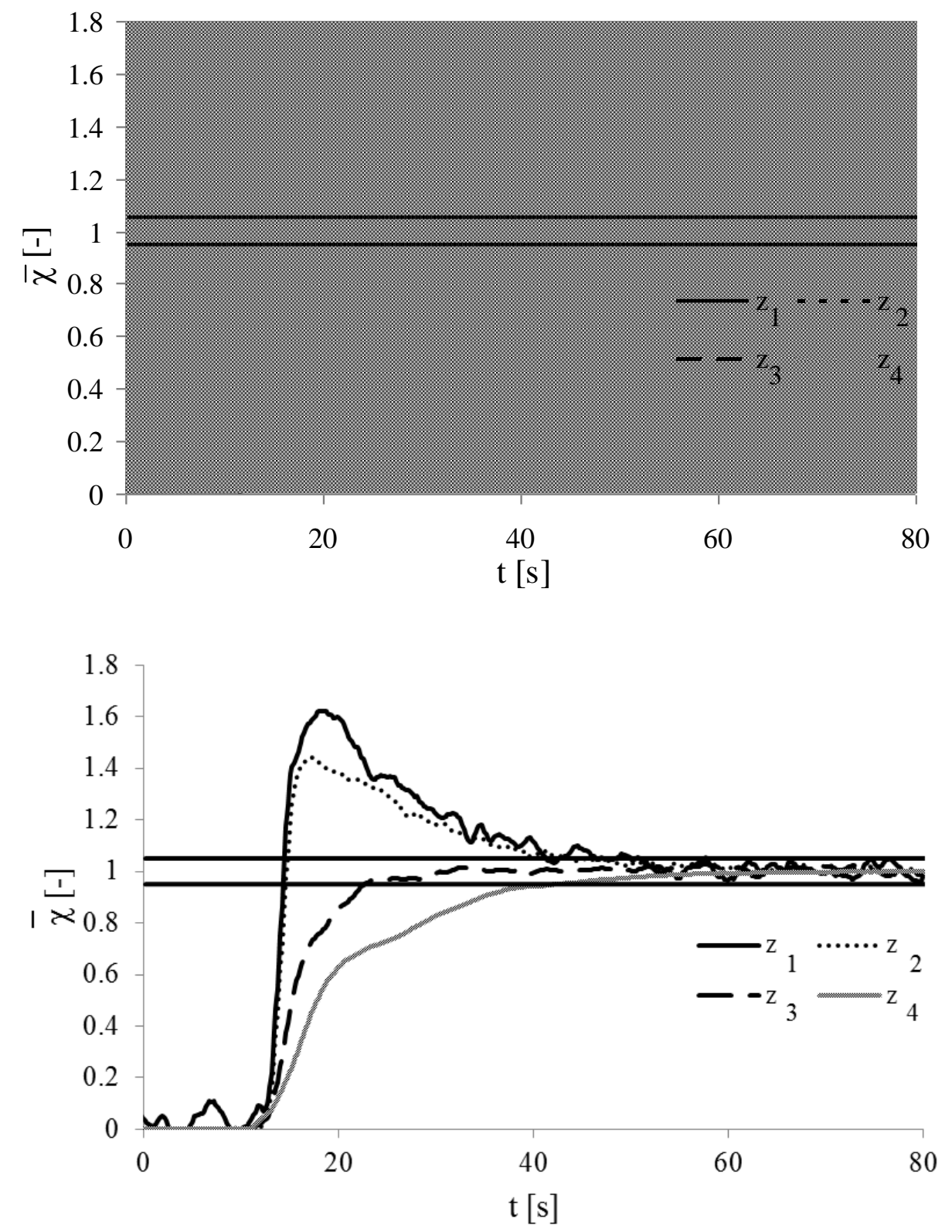

(a)

(b) 
Fig. 3. Time series of normalized local conductivity averaged on the measurement plane. $\left(\mathrm{d}_{\mathrm{p}}=385 \mu \mathrm{m}, \mathrm{X}=0.43, \mathrm{~N}=500 \mathrm{rpm}\right.$, tracer addition: $\mathrm{A1}$ ). (a) raw data; (b) moving window averaged data. The horizontal lines correspond to $\pm 5 \%$ of the final normalized conductivity.

Afterwards, the liquid mixing time, t95, is identified, as the maximum of the values calculated from the four averaged normalized conductivity curves, thus extending the usual quantitative estimations based on single points methods to a whole-field approach.

\subsection{Definition of intensity, scale and rate of change of mixing}

For a more extensive evaluation of the liquid mixing dynamics in the slurry stirred tank, the local conductivity data on adjacent measurement planes are interpolated, providing information on the vessel volume bounded between the lower and the upper measurements' planes $\left(\mathrm{z}_{1}\right.$ and $\left.\mathrm{z}_{4}\right)$. The requirement of volume based evaluations of the mixing time was already highlighted by Yeoh et al. (2005), whose Large Eddy Simulations (LES) revealed significant variations of the time history of the scalar concentration across the vessel volume even for single-phase systems. Based on the volumetric data, the intensity, the scale and the rate of change of mixing during the tracer homogenization are estimated, following the general mixing and segregation definitions recently discussed by Kukukova et al. (2009).

The intensity of segregation is usually calculated as the Coefficient of Variation (CoV) of the local concentration, the scale of segregation represents the distribution of length scales or the arrangement of the fluid volumes in the mixing field, while the rate of change addresses the effectiveness of the equipment in the reduction of segregation. These three parameters either referred to segregation or to mixing have never been estimated so far for the liquid homogenization in solid-liquid stirred tanks. In the following, mixing will be considered for the parameters' definition instead of segregation, being the mixing time the classical fundamental indicator adopted for batch mechanical agitation.

The dynamic distribution of the well mixed zones is firstly identified based on a fixed homogeneity threshold, as already suggested by Yeoh et al. (2005). The $x=95 \%$ and $x=90 \%$ thresholds of homogeneity degree are selected here. The former is the standard value adopted for single phase systems, while the latter is more suitable for two phase conditions because of the intrinsic liquid conductivity fluctuations due to the dispersed phase. Based on the selected threshold, each cell of the volume can be classified either well mixed or not sufficiently mixed. As a result, during the tracer homogenization, the total well mixed volume, $\mathrm{V}_{\mathrm{M}}$, and the total surface containing the well mixed zones, $A_{M}$, can be calculated as a function of time. 
When the fixed homogenization threshold is achieved, $V_{M}$ and $A_{M}$ coincide with the volume and the external surface of the measurement zone, respectively. The instantaneous distribution of the well mixed zones on a vessel vertical cross sections and the corresponding boundaries between the well mixed and poorly mixed zones at a particular time are shown in Fig. 4, as an example of the typical results of the calculations.

The well mixed volume provides an indication of the intensity of mixing in the investigated vessel portion. It is depicted together with the $\mathrm{CoV}$, which is often adopted as a measure of the intensity of segregation, for a single-phase experiment in Fig. 5. As can be observed, the two parameters offer information on different aspects of the homogenization process. The $\mathrm{CoV}$ variation is sharp immediately after the tracer injection during the macromixing stage, when the concentration is far from the well mixed condition in the whole vessel region, while the $\mathrm{V}_{\mathrm{M}}$ change is very slow until the meso-mixing process start to become significant.

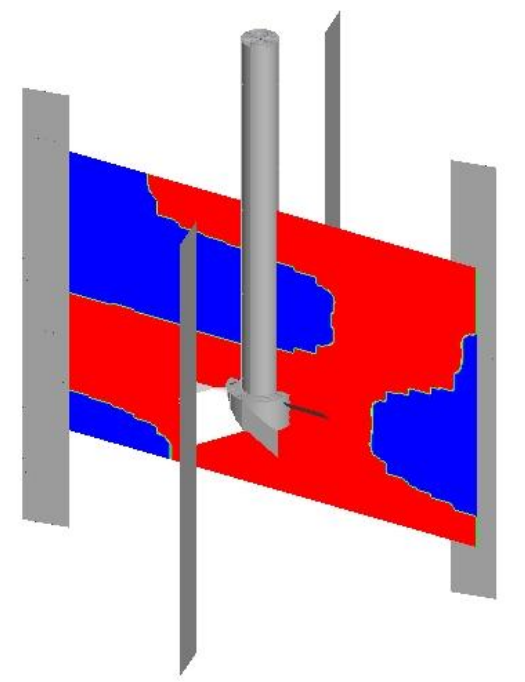

(a)

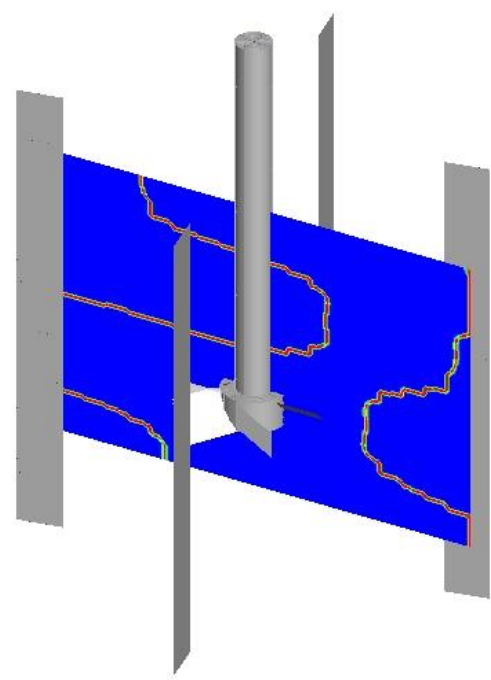

(b)

Fig. 4. (a) Instantaneous distribution of well mixed (blue) and poorly mixed (red) cells; (b) Boundary between the two zones. (For interpretation of the reference to colour in this figure legend, the reader is referred to the web version of this article.)

The scale of mixing giving information on the arrangement of fluid volumes in the mixed region can be estimated as the equivalent diameter, $d_{\mathrm{eq}}$, which is defined as the ratio between $6 \times V_{M}$ and $A_{M}$. Similarly to the Sauter diameter, the equivalent diameter corresponds to the diameter of a sphere having the same ratio of external surface to volume as the measured tracer plum, being this parameter effective in describing the dispersion of the tracer, which depends on mass transfer. The third dimension of segregation proposed by Kukukova et al. (2009), that is related to both the intensity and the scale of segregation, is the rate of change of 
segregation or the exposure of the process. It can be estimated through the standard definition of mass transfer rate, that depends on a mass transfer coefficient, giving the strength of the interaction between the liquid cells at different conductivity, the concentration gradient and the interfacial area. The time evolution of the equivalent diameter during the homogenization, $\Delta \mathrm{d}_{\mathrm{eq}} / \Delta \mathrm{t}$, is proposed here as a measure of the exposure of the liquid homogenization process.

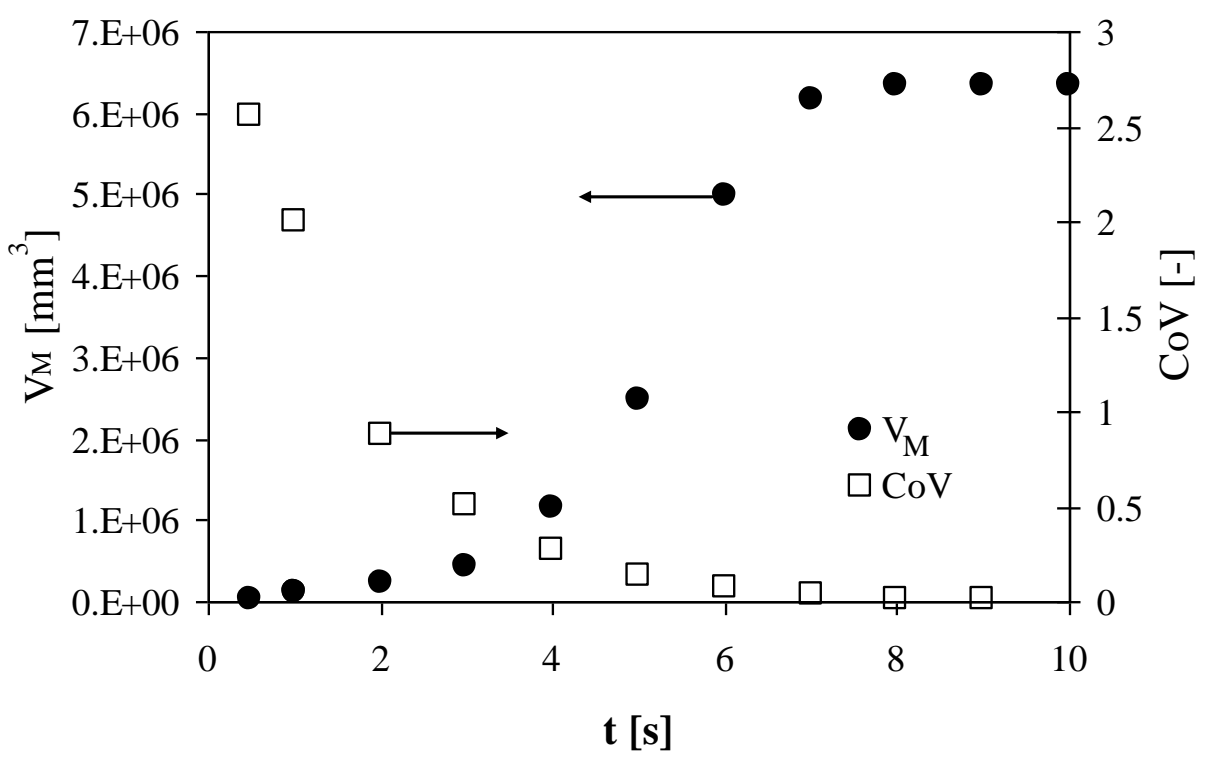

Fig. 5. Time evolution of $V_{M}$ and the CoV. Single-phase, $N=500 \mathrm{rpm}$.

\section{Results and discussion}

The liquid homogenization dynamics for the slurry, as obtained with the three tracer addition positions, are depicted for the bigger particles and one combination of $\mathrm{N}$ and $\mathrm{X}$ in Fig. 6. As can be observed, the normalized local conductivity averaged over each plane, $\bar{\chi}(t)$, takes tens of seconds to achieve a mixedness level of $95 \%$. Under the same agitation conditions, the $t_{95}$ value in single-phase flow is equal to about $5 \mathrm{~s}$, either based on the correlation of Grenville and Nienow (2004) and on the direct ERT measurement. The significantly longer mixing time shown in Fig. 6 is in agreement with previous findings obtained with other measurement techniques for similar systems (e.g. Bujalski et al., 1999).

Also, the results reported in Fig. 6 show that for this specific solid-liquid system the addition position and location of the concentration measurement of the tracer do not dramatically affect the global mixing time. The bigger $t_{95}$ value is obtained with the A3 injection position, being the maximum value equal to $44 \mathrm{~s}$ on the $\mathrm{z}_{1}$ plane and the standard deviation, $\mathrm{SD}_{\mathrm{p}}$, of the 
values on the four measurement planes equal to $10 \mathrm{~s}$. The difference among the maximum values obtained with the three injection positions exhibits a standard deviation, $\mathrm{SD}_{\mathrm{ip}}$, equal to $4.4 \mathrm{~s}$.

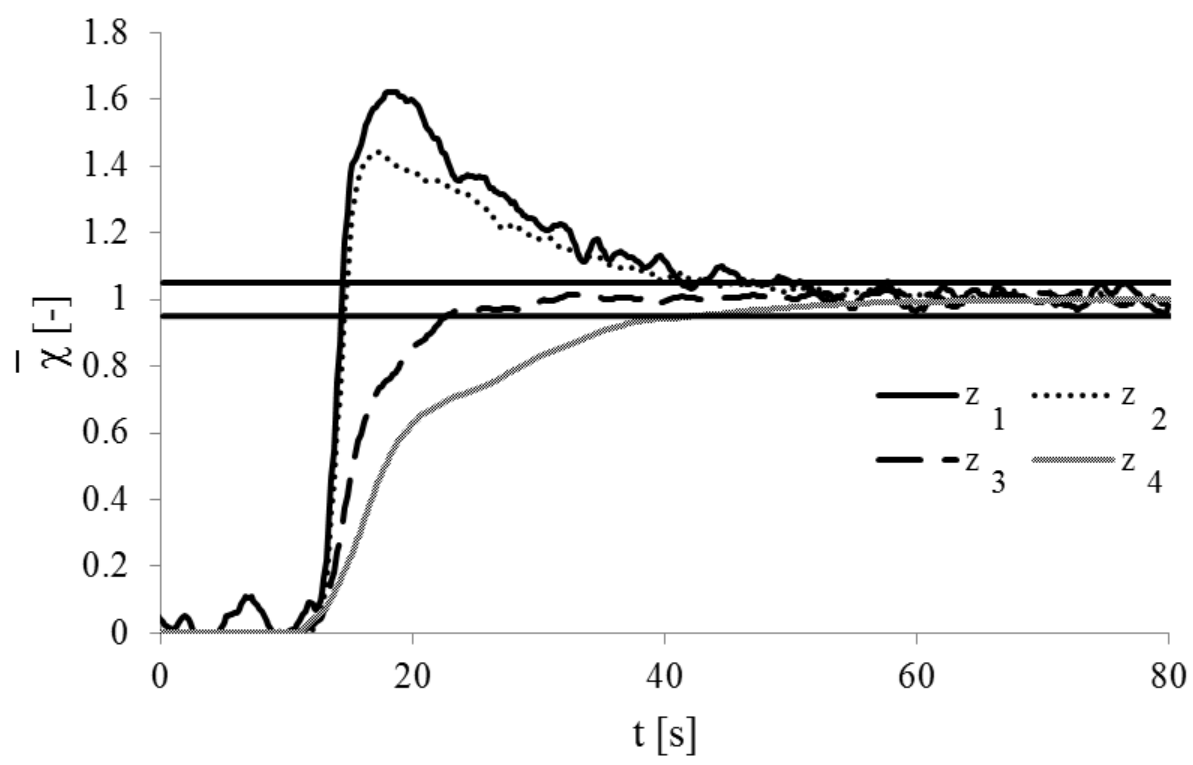

(a)

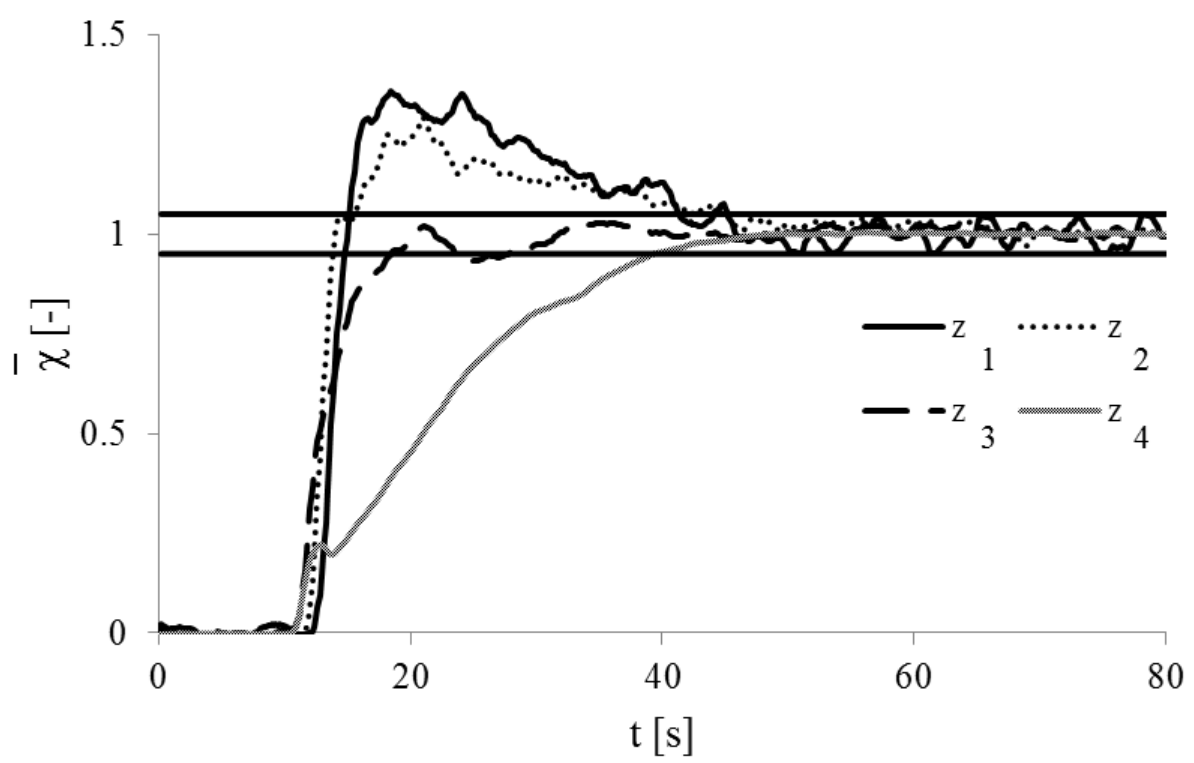

(b) 


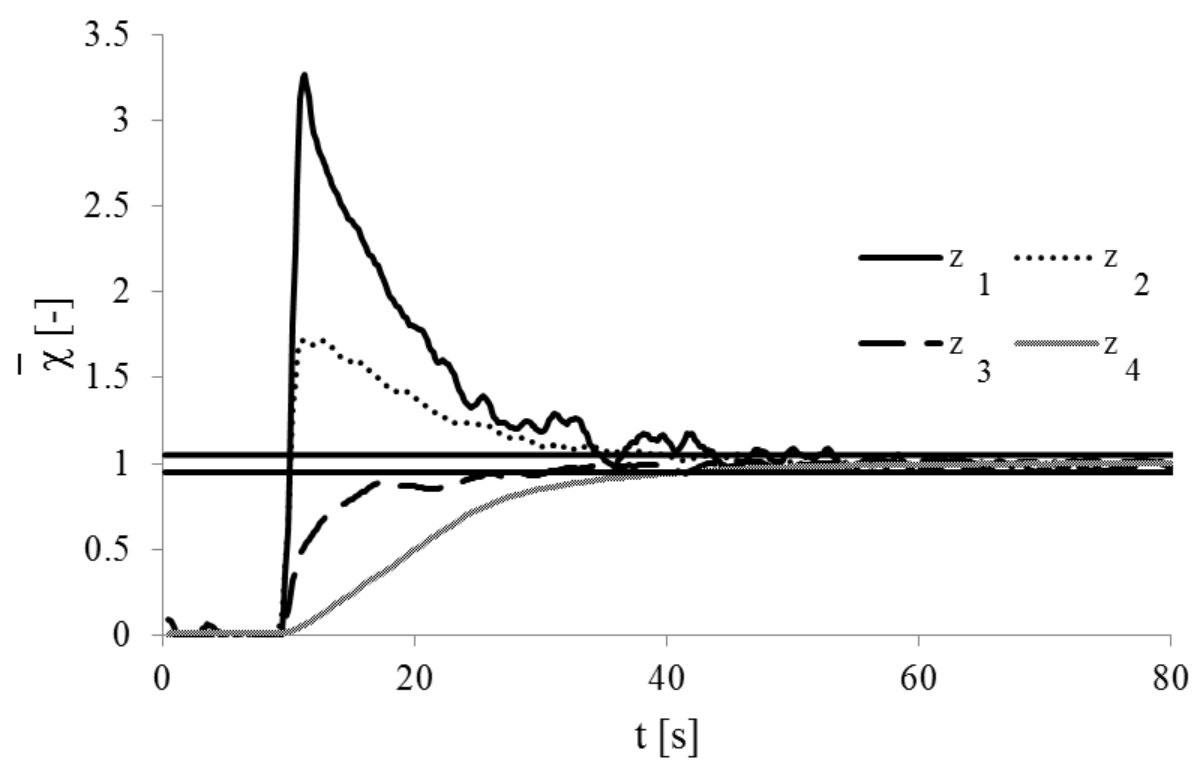

(c)

Fig. 6. Dependency of the liquid homogenization dynamics on the tracer injection position. (a) A1 (top centred); (b) A2 (top wall); (c) A3 (bottom centred). $\mathrm{d}_{\mathrm{p}}=385 \mu \mathrm{m}, \mathrm{N}=500 \mathrm{rpm}$, $\mathrm{X}=0.43$. The horizontal lines correspond to $\pm 5 \%$ of the final normalized conductivity.

Different results are instead obtained with the smaller particles slurry at the same impeller speed and solid loading, as shown in Fig. 7. The dependency on the injection position is apparent, being the homogenization dynamics much slower for the bottom addition than for the top (maximum t9s $=82 \mathrm{~s}, \mathrm{SD}_{\mathrm{p}}=6 \mathrm{~s}, \mathrm{SD}_{\mathrm{ip}}=21 \mathrm{~s}$ ).

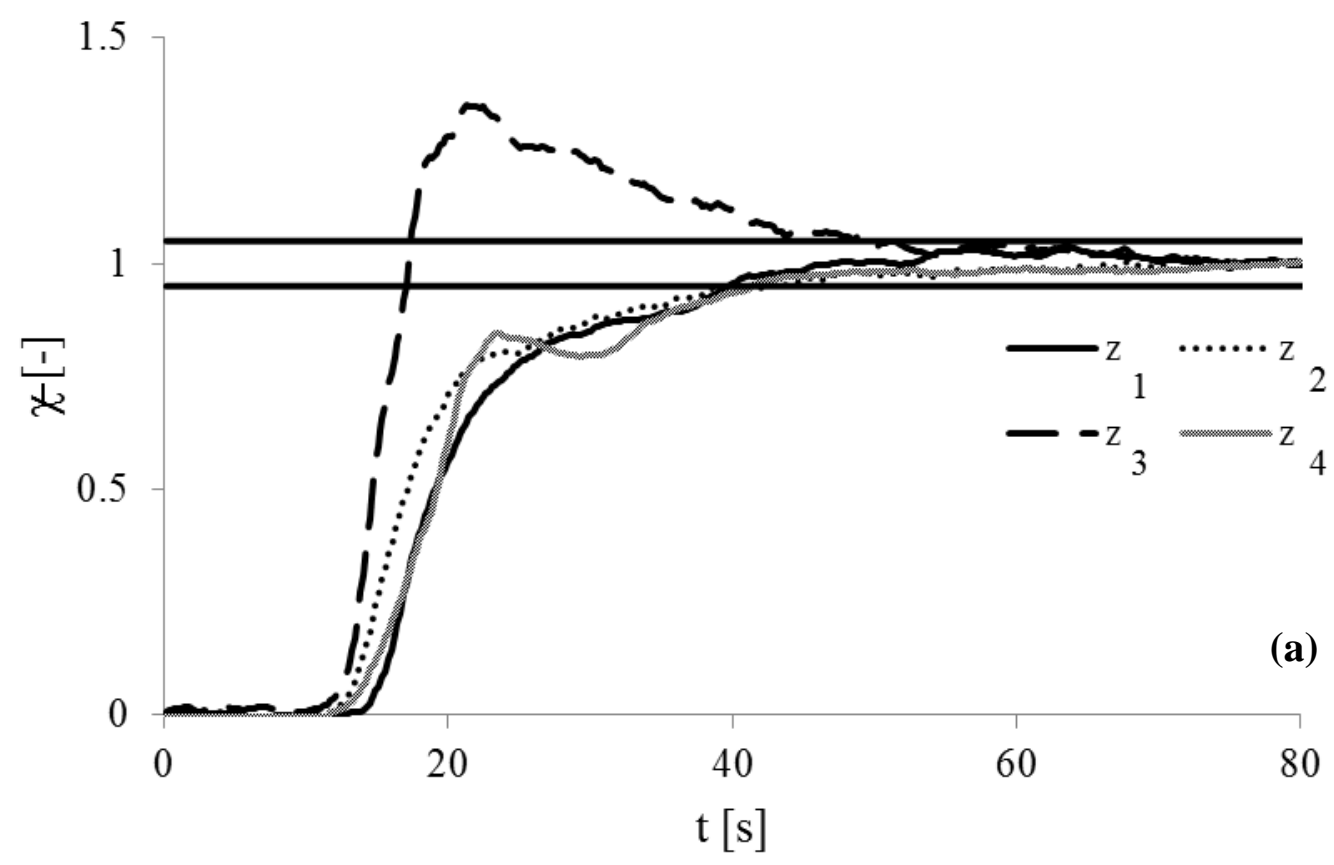



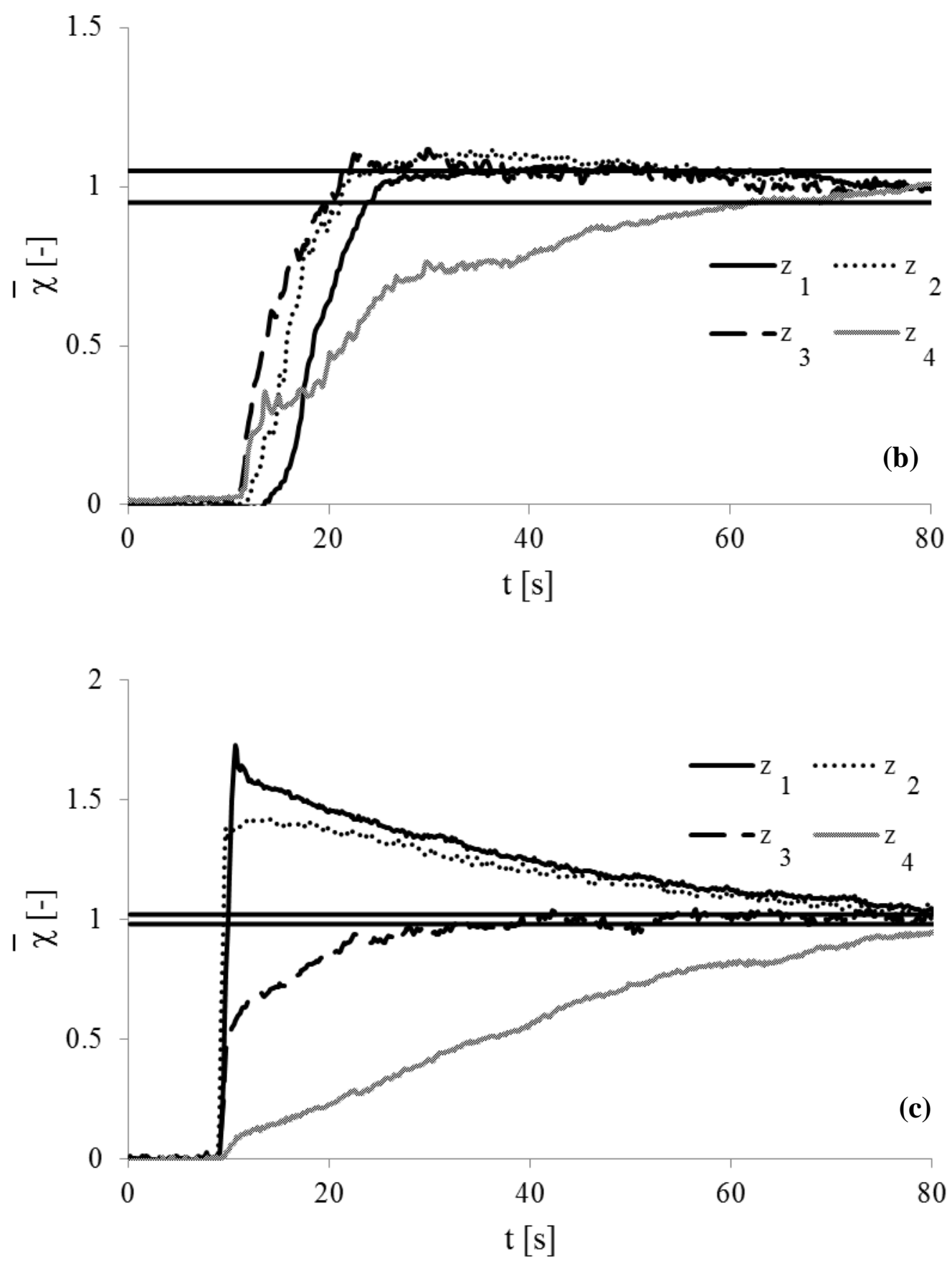

Fig. 7. Dependency of the liquid homogenization dynamics on the tracer injection position. (a) A1 (top centred); (b) A2 (top wall); (c) A3 (bottom centred). $d_{p}=138 \mu \mathrm{m}, \mathrm{N}=500 \mathrm{rpm}$, $X=0.43$. The horizontal lines correspond to $\pm 5 \%$ of the final normalized conductivity.

It is worth observing that the same agitation speed corresponds to different suspension conditions for the two particle sizes, thus affecting the local fluid dynamics, the overall amount of suspended particles and their spatial distribution (Carletti et al., 2014). 
The values of t95 estimated as described above at the two different impeller speeds are summarized in Fig. 8. The different influence of the injection point depending on the particle size is apparent. In all cases, significantly shorter times are obtained at increased impeller speed, as expected. Much higher values are always obtained with respect to the values measured under single phase conditions.

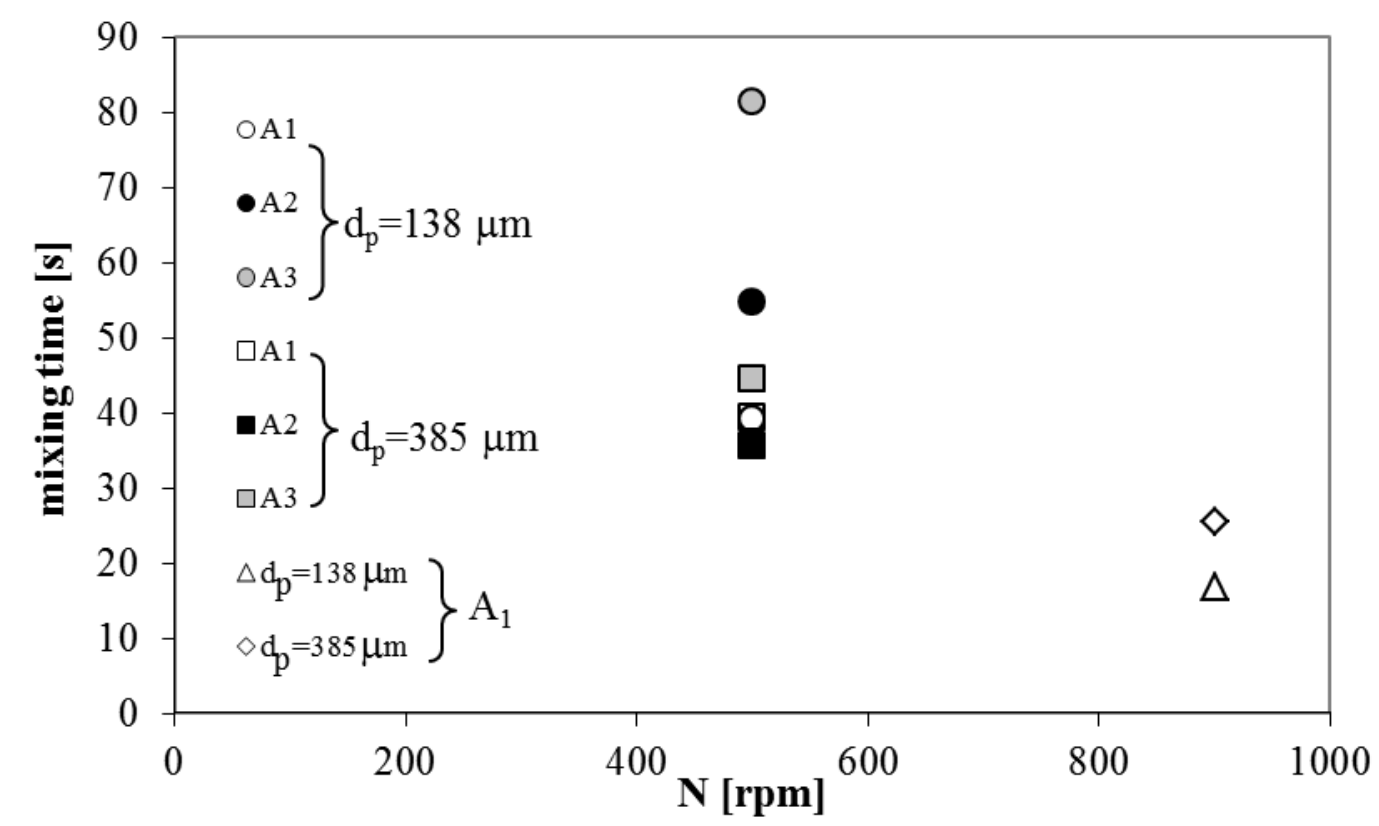

Fig. 8. Effect of impeller speed and injection position on the mixing time $t_{95}$.

These results further strengthen the conclusions of the previous investigations on the mixing time in dense suspensions and its relationship with the complex interactions between the particles and the liquid fluid dynamics (Kraume, 1992, Bujalski et al., 1999; Micheletti et al., 2003). As a result, comprehensive correlations based on lumped parameters, which are instead successful for the single-phase vessels, are not available and the collection of local information and their analysis over the vessel volume is suggested for a more reliable assessment of the mixing time. Besides, Computational Fluid Dynamics (CFD) based methods remain at present the only viable tools for the mixing time predictions in slurry stirred tanks.

The information provided by ERT can be further analysed on a more detailed basis. In particular, the instantaneous local normalized liquid conductivity on each plane can be adopted to obtain the spatial reconstruction of tracer homogenization over time in the volume between $\mathrm{z}_{1}$ and $\mathrm{z}_{4}$. To this end, the interpolation of the data collected at the different elevations is performed, similarly to what is done for the spatial solid distribution (e.g. 
Tahvildarian et al., 2011). Selected snapshots of the injected tracer plume are identified in Fig. 9 by the iso-surface of the normalized conductivity equal to 1.1 for the case of the top-wall injection position (A2) in the finer particles slurry. Overlapped to the time depended evolution of the tracer distribution, the steady state iso-surface of the dimensionless conductivity equal to 0.9 measured before the tracer addition is also shown, since it provides a close representation of the solid-liquid interface (Carletti et al., 2014). The instantaneous tracer spatial distribution together with the shape of clear liquid layer are very useful outcomes of ERT for the detailed characterization of opaque slurry. As can be observed, the concentrated tracer plume reaches the impeller plane a few seconds after its entrance from the top and its progressive homogenization lasts several tens of seconds.
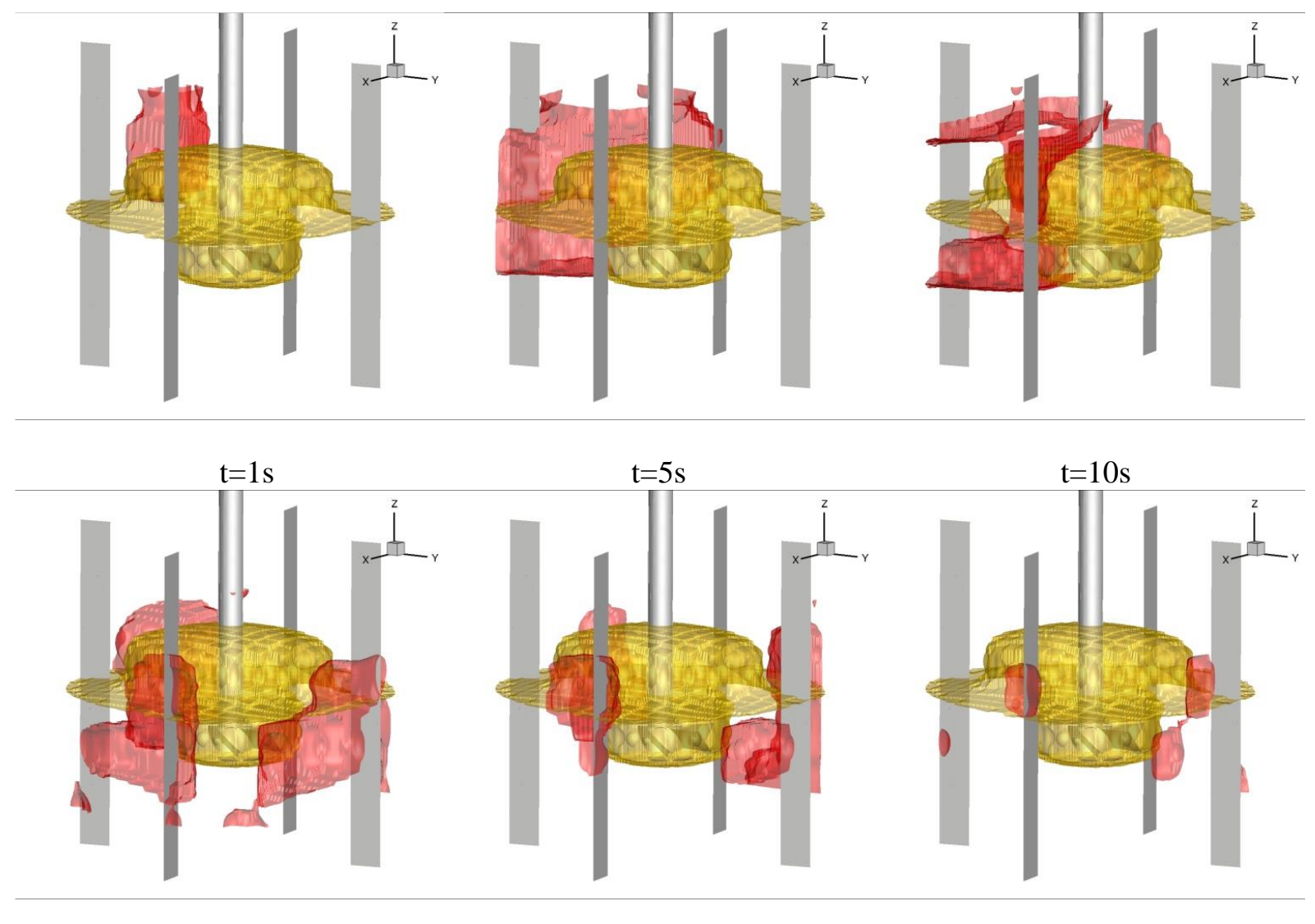

$$
\mathrm{t}=40 \mathrm{~s} \quad \mathrm{t}=40 \mathrm{~s} \quad \mathrm{t}=60 \mathrm{~s}
$$

Fig. 9. Instantaneous iso-surface of dimensionless conductivity equal to $90 \%$ for steady state solid-liquid suspension (yellow) and iso-surface of normalized conductivity equal to $110 \%$ after the tracer injection from the top close to the wall (red). $d_{p}=138 \mu \mathrm{m}, \mathrm{N}=500 \mathrm{rpm}, \mathrm{X}=0.43$. (For interpretation of the reference to colour in this figure legend, the reader is referred to the web version of this article.) 


\subsection{Intensity, scale and rate of change of mixing}

The tracer homogenization process under the different conditions is further analysed based on the parameters defined in Sect. 2.2, whose dynamic evolution in single-phase conditions for $\mathrm{N}=500 \mathrm{rpm}$ is shown in Fig. 10 for both the thresholds of $x=90 \%$ and $x=95 \%$.
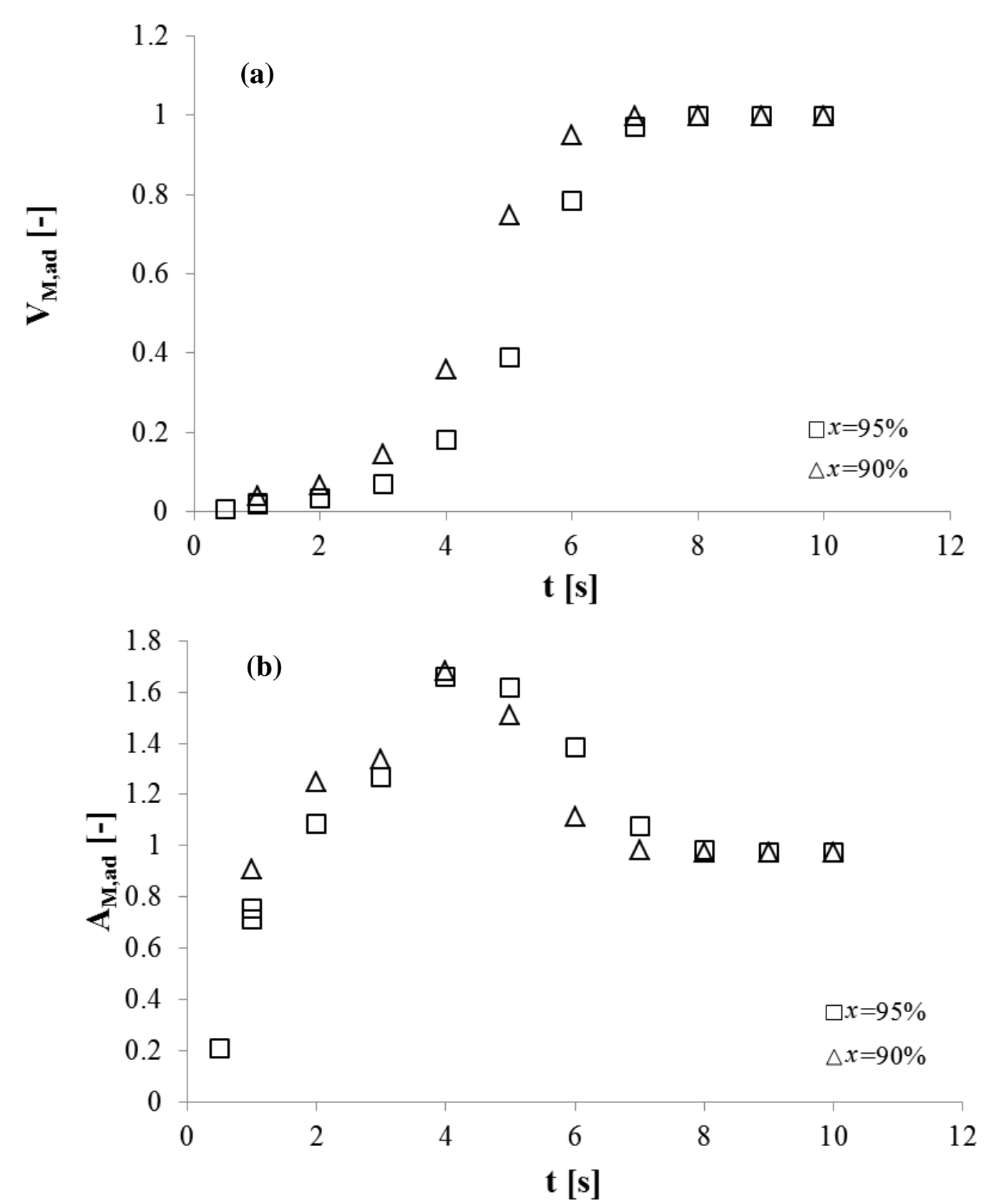

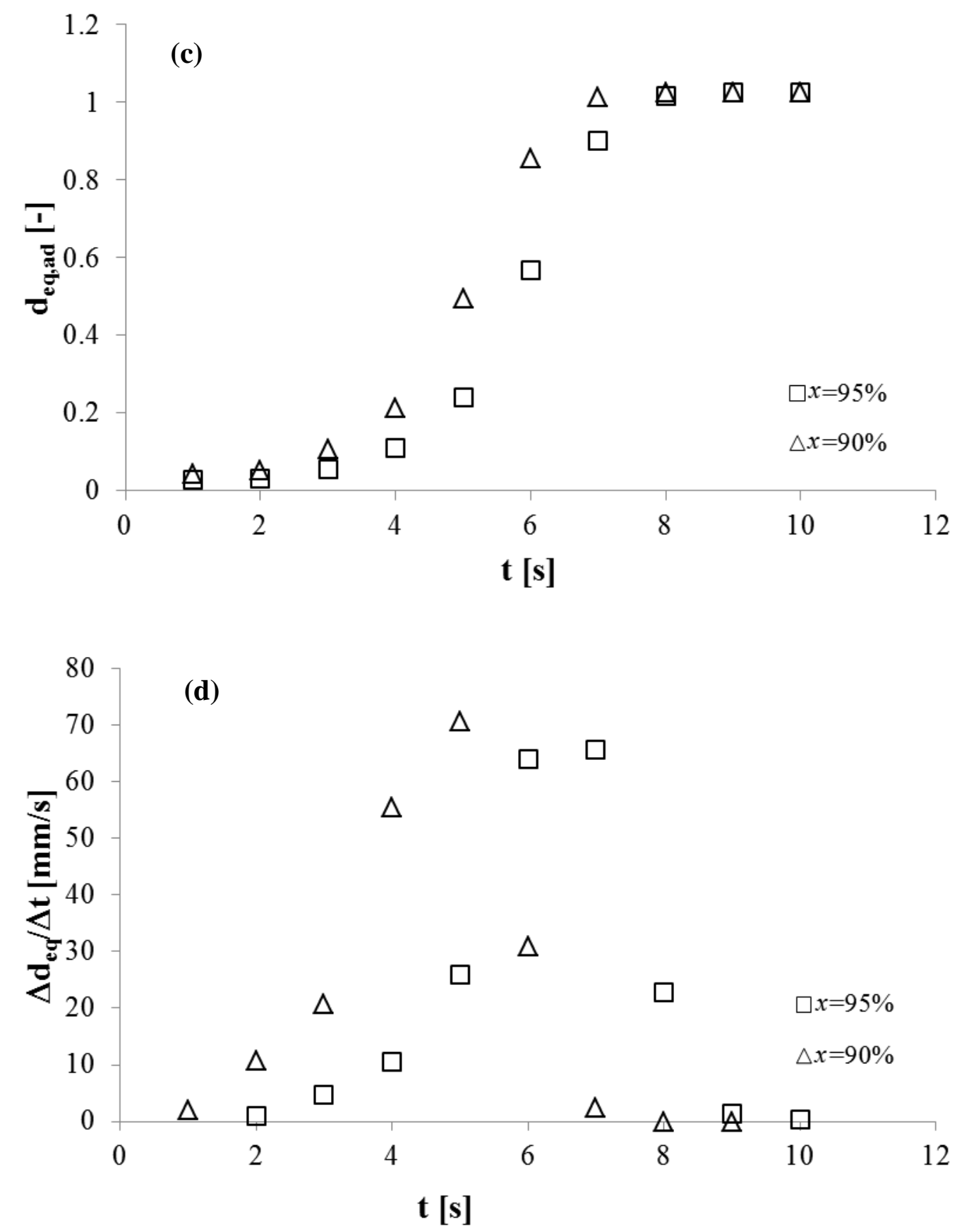

Fig. 10. Time evolution of the mixing parameters (a) $\mathrm{V}_{\mathrm{M} \text {,ad }}$; (b) $\mathrm{A}_{\mathrm{M}, \mathrm{ad}}$; (c) $\mathrm{d}_{\mathrm{ec}}$ (d) $\Delta \mathrm{d}_{\mathrm{eq}} / \Delta \mathrm{t}$ during the tracer homogenization in the single-phase stirred tank, $\mathrm{N}=500 \mathrm{rpm}$.

The dimensionless well mixed volume, $\mathrm{V}_{\mathrm{M}}$,ad, that is $\mathrm{V}_{\mathrm{M}}$ divided by the measurement volume, exhibits an increasing trend (Fig. 10a), that can be divided in two steps. Just after the injection of the tracer, the well mixed volume increases much slowly than after a few seconds from the injection. This two steps behaviour of the mixing progress variations was already observed by Yeoh et al., (2005) from LES results. Finally, $\mathrm{V}_{\mathrm{M} \text {,ad }}$ sits on the constant value of 1, as soon as the tracer reaches the fixed thresholds value in the whole volume between the lower and the 
upper electrodes. As expected, the higher is the desired homogenization level the longer is the time required to achieve it.

The evolution of the dimensionless well mixed area, $A_{M, a d}$, that is $A_{M}$ divided by the vessel lateral surface limited by the lower and the upper measurement planes plus two times the

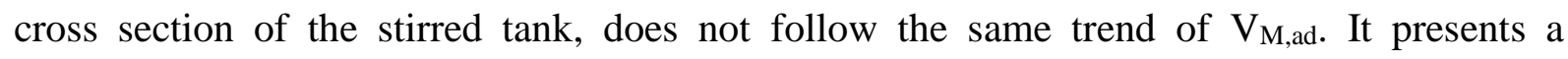
maximum value at about 4-5 seconds from the injection, subsequently it decreases approaching the external surface of the cylinder on which the measurement planes are located. Slight differences due to the selected $x$ value are observed. The $\mathrm{d}_{\mathrm{eq}}$ evolution is qualitatively the same of $\mathrm{V}_{\mathrm{M}, \mathrm{ad}}$, while $\Delta \mathrm{d}_{\mathrm{eq}} / \Delta \mathrm{t}$ presents a maximum whose location is affected from the threshold, then it decreases to zero.

For the solid-liquid conditions, the threshold of $90 \%$ is selected for smoothing out the physical fluctuations of the signal due to the particles passage. Overall, the same parameters exhibit significant differences in the solid-liquid systems with respect to the single-phase conditions as shown in Figs. 11 and 12, although the two steps trend of $\mathrm{V}_{\mathrm{M} \text {,ad }}$ is confirmed.

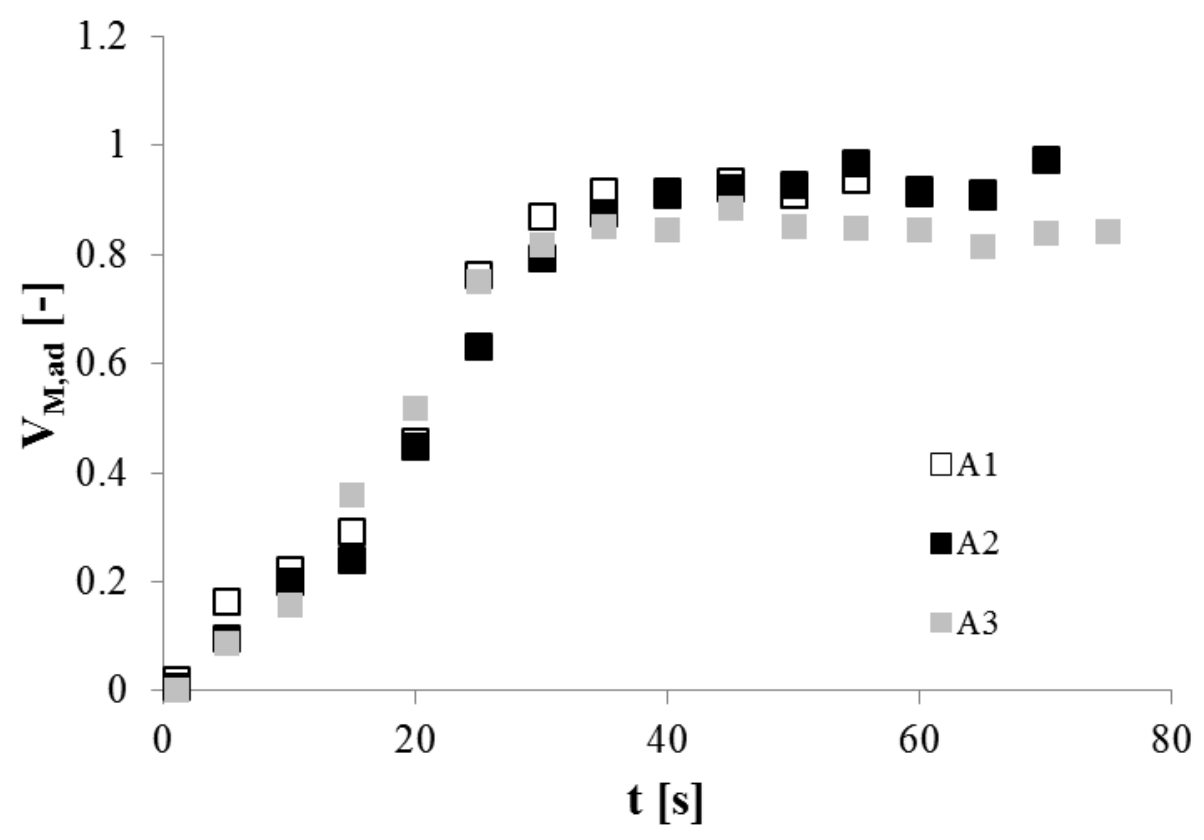

Fig. 11. Effect of the injection position on $\mathrm{V}_{\mathrm{M} \text {,ad }}\left(\mathrm{d}_{\mathrm{p}}=385 \mu \mathrm{m}, \mathrm{N}=500 \mathrm{rpm}, \mathrm{X}=0.43\right)$.

As for the effect of the tracer addition position, $\mathrm{V}_{\mathrm{M} \text {,ad }}$ is quite similar for the coarser particles (Fig 11), while with the finer (Fig. 12) about 20 seconds after the injection the dimensionless well mixed volume exhibits a much steeper increase with the top centred injection. 


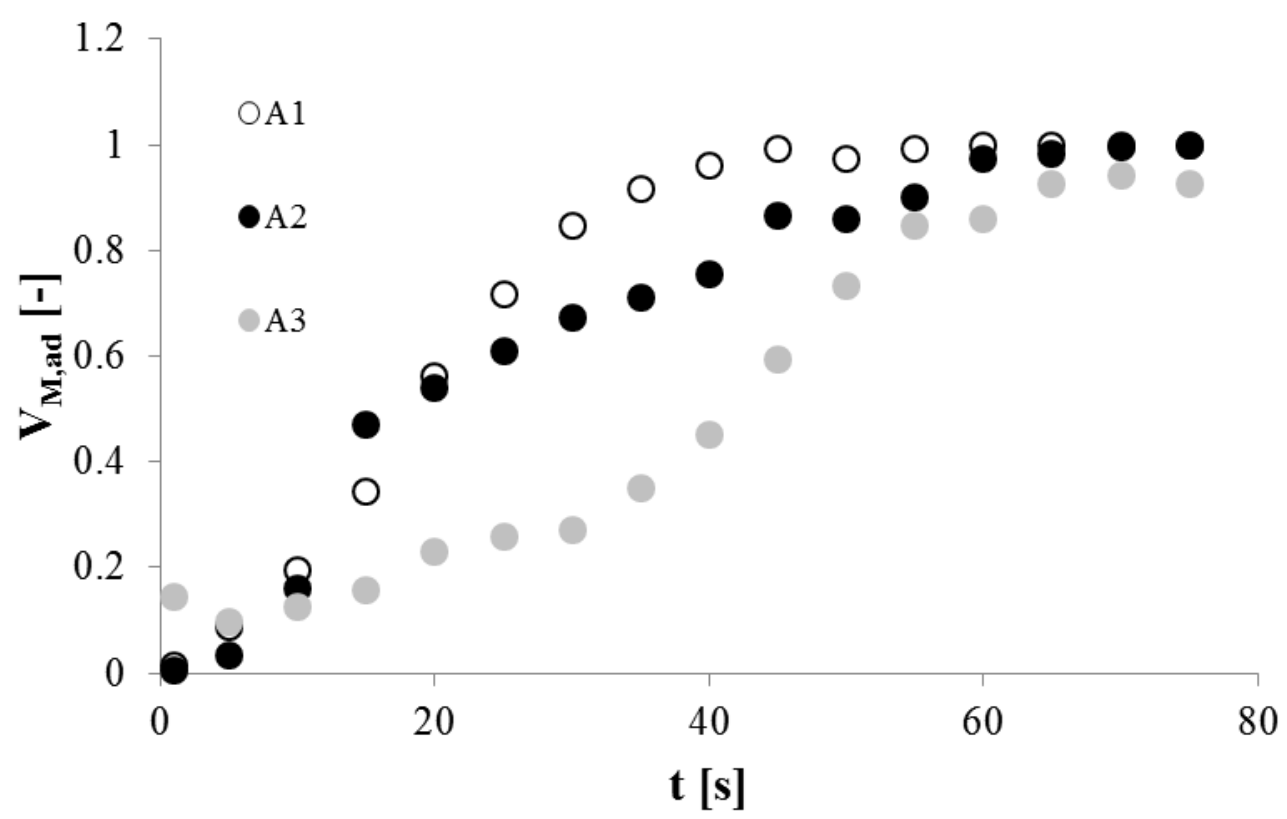

Fig. 12. Effect of the injection position on $\mathrm{V}_{\mathrm{M}, \mathrm{ad}}\left(\mathrm{d}_{\mathrm{p}}=138 \mu \mathrm{m}, \mathrm{N}=500 \mathrm{rpm}, \mathrm{X}=0.43\right)$.

For the other two cases, the curves are very close to each other. The different slopes of the curves is an indirect indication of the different local hydrodynamics conditions experienced by the tracer in the vessel, which depend on the injection point. Overall, the scale of segregation can be highly or negligibly affected by the injection point, depending on the specific features of the dense solid-liquid system.

The effect of the impeller speed is shown in Fig. 13. As expected, the well mixed volume increases faster the higher the impeller speed is. 


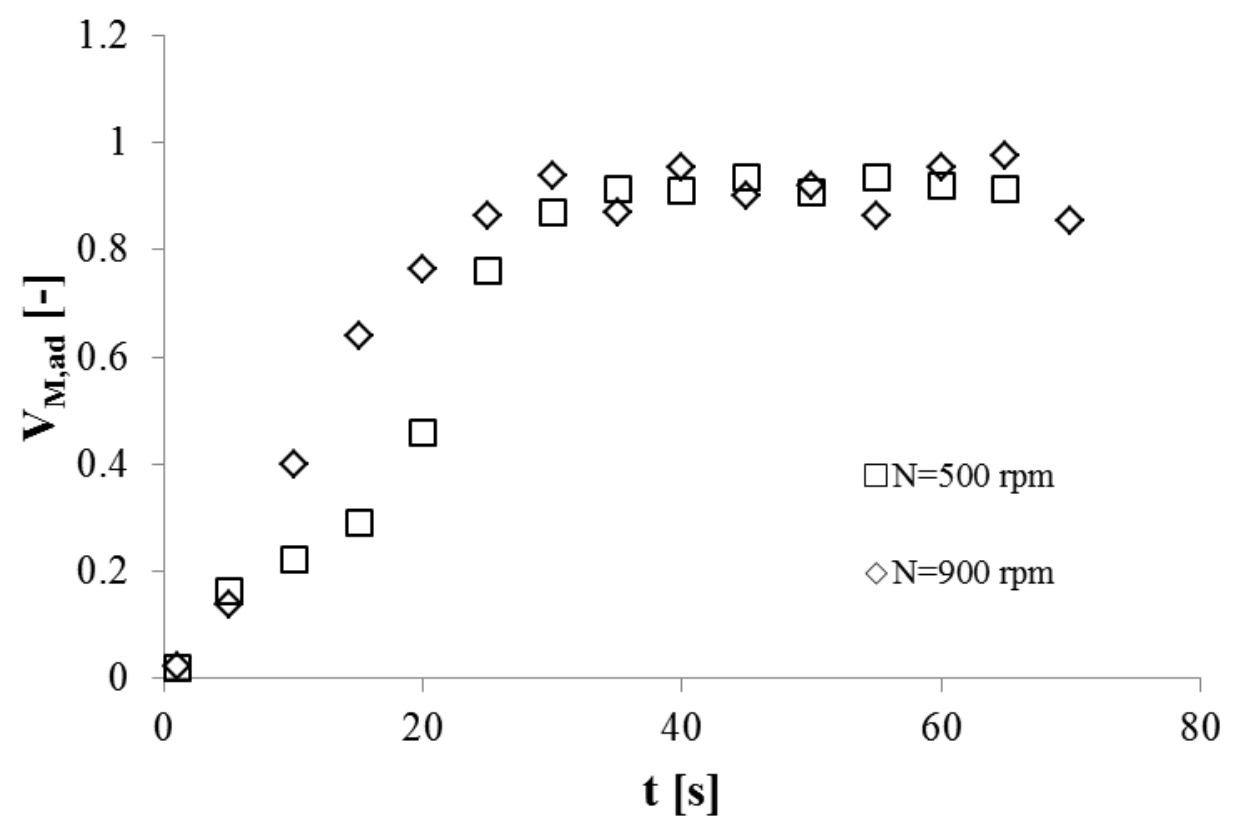

Fig. 13. Effect of the impeller speed on $\mathrm{V}_{\mathrm{M}, \mathrm{ad}}\left(\mathrm{d}_{\mathrm{p}}=385 \mu \mathrm{m}, \mathrm{X}=0.43\right.$, injection on the centred top position, A1).

The rate of change of the liquid mixing process can be followed analysing the time evolution of the incremental ratio of the dimensionless mixed volume, $\Delta \mathrm{V}_{\mathrm{M}, \mathrm{ad}} / \Delta \mathrm{t}$ (Fig. 14a) and of the dimensionless area, $\Delta \mathrm{A}_{\mathrm{M}, \mathrm{ad}} / \Delta \mathrm{t}$ (Fig. 14b). As expected, $\Delta \mathrm{V}_{\mathrm{M}, \mathrm{ad}} / \Delta \mathrm{t}$ is always positive, since the well mixed volume size always increases, but it is not constant. The variation of the mass transfer driving force and the change of the surface available for the mass transfer are the main reasons of the observed variation, which exhibits a maximum value at about $\mathrm{t}=20 \mathrm{~s}$.

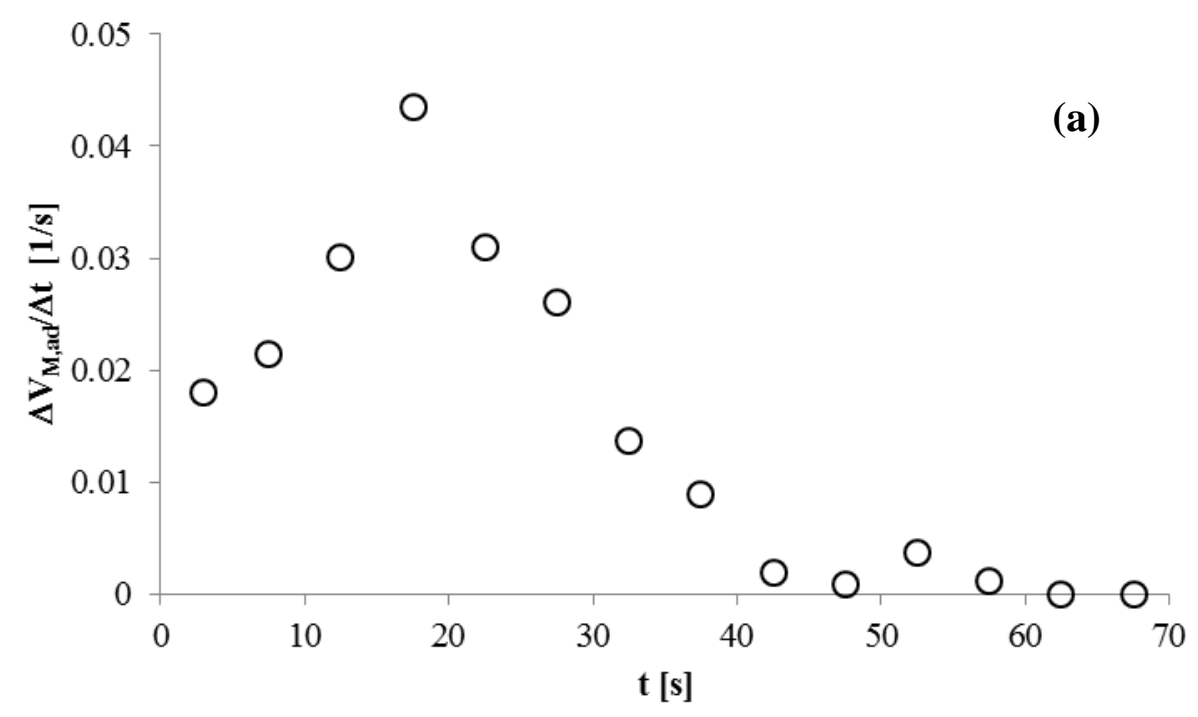




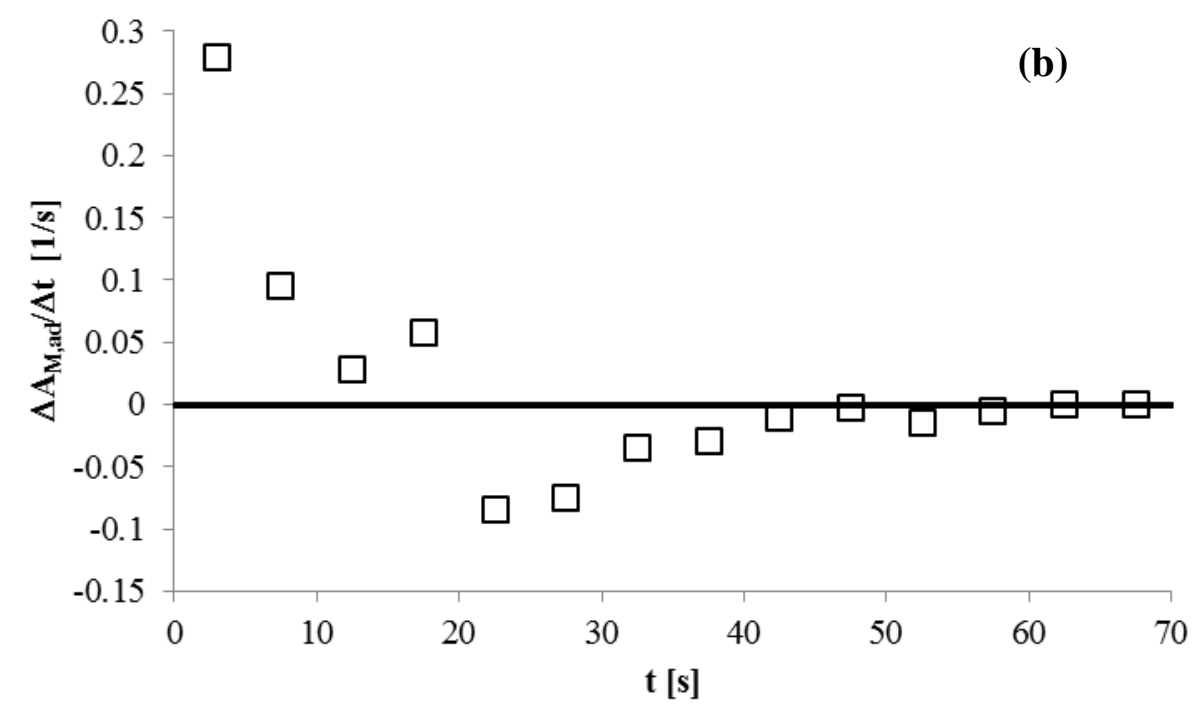

Fig. 14. Time evolution of incremental ratio of a) $V_{M, a d}$ and b) $A_{M, a d}(d p=138 \mu m, X=0.43$, injection on the centred top position, A1).

It is worth observing that $\Delta \mathrm{A}_{\mathrm{M}, \mathrm{ad}} / \Delta \mathrm{t}$ is positive up to $\mathrm{t}=20 \mathrm{~s}$, while afterwards it becomes negative. This means that up to $t=20 \mathrm{~s}$, the surface of the well mixed volume increases, than the well mixed zones merge and the external area of the well mixed volume decreases.

The homogenization characteristics in single phase and two phase systems are compared in Fig. 15, where the $\Delta \mathrm{V}_{\mathrm{M}, \mathrm{ad}} / \Delta \mathrm{t}$ is plotted against $\Delta \mathrm{A}_{\mathrm{M}, \mathrm{ad}} / \Delta \mathrm{t}$. The results show the dampening of mass transfer due to the solids as compared with the single-phase cases as can be noticed comparing the maximum of $\Delta \mathrm{V}_{\mathrm{M}, \mathrm{ad}} / \Delta \mathrm{t}_{\text {single phase }}$ that is greater than $\Delta \mathrm{V}_{\mathrm{M}, \mathrm{ad}} / \Delta \mathrm{t}_{\mathrm{two}}$ phase.

Also, the maximum value of the positive incremental ratio of the dimensionless mixed area, $\Delta \mathrm{A}_{\mathrm{M}, \mathrm{ad}} / \Delta \mathrm{t}$, that gives an indication of the separation of the well mixed regions, is higher than that of the maximum negative value, associated with the merging of the well mixed regions both in single and two-phase systems. 


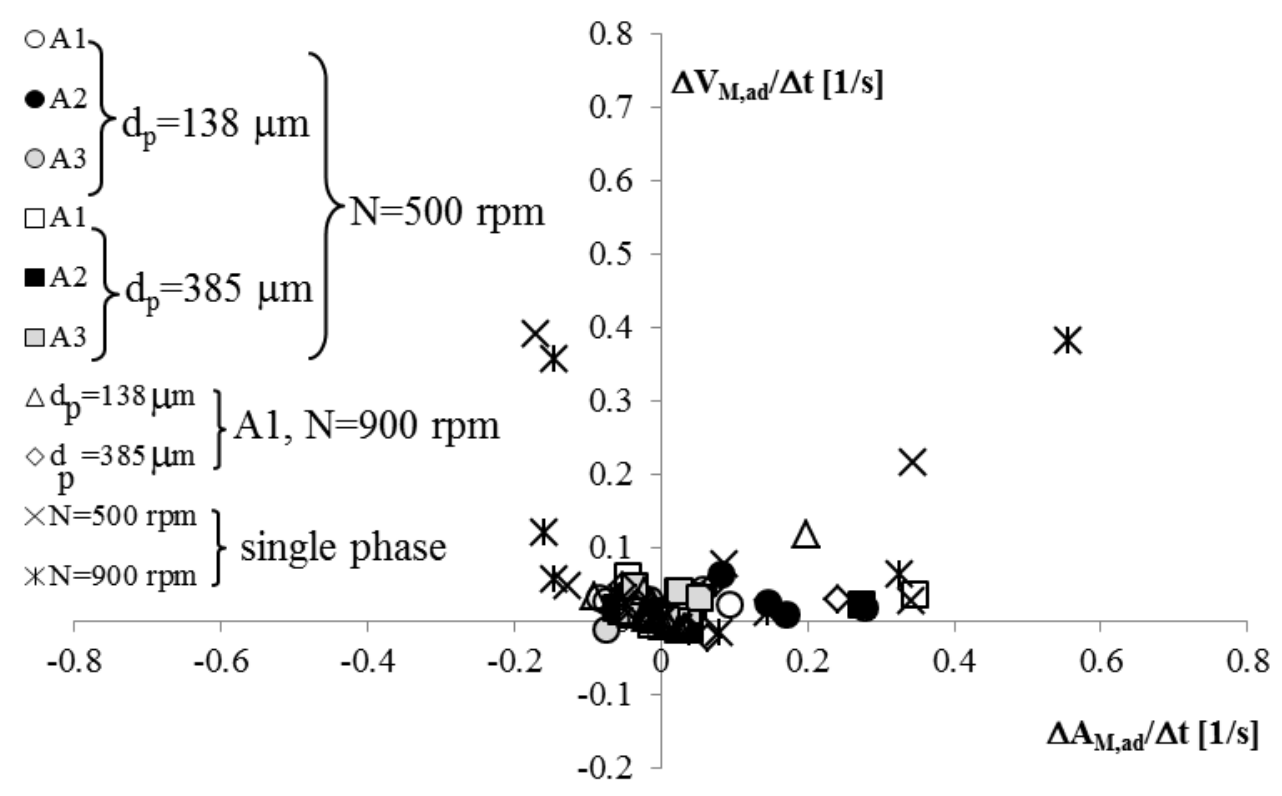

Fig. 15. Rate of change of $\mathrm{V}_{\mathrm{M} \text {,ad }} v s$ rate of change of $\mathrm{A}_{\mathrm{M} \text {,ad. }}$

As an alternative to the $t_{X}$, the effective time required to achieve the complete liquid mixing can be estimated from the dimensionless well mixed volume, $\mathrm{V}_{\mathrm{M}, \text { ad. The difference between }}$ the two methods can be estimated from the results shown in Fig. 16, where the dimensionless $\mathrm{V}_{\mathrm{M}, \text { ad }}$ is reported as a function of a dimensionless time, that is the time divided by $\mathrm{t}_{\text {mix }}$ (either

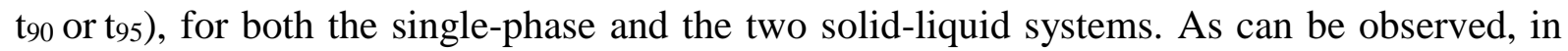
all cases, for $\mathrm{t}=\mathrm{t}_{\mathrm{mix}}$ the well mixed volume is lower than the liquid volume corresponding to the complete homogenization. This further confirms that the size and the position of the measurement probes critically affects the experimental evaluation of the mixing time (Kukukova et al., 2008).

Overall, as compared with the sole liquid mixing time estimation, the measurement technique and the data processing route proposed in this work provide together a comprehensive and quantitative estimation of the liquid homogenization process in the vessel volume, which may lead to significantly different conclusions with respect to both single points quantitative methods and qualitative whole field approaches. It is worth observing that by the ERT and the data appropriate processing all the drawbacks of the classical experimental methods for the mixing time estimation (Brown et al., 2004) are overcame, without any limitations for opaque and/or dense systems. 


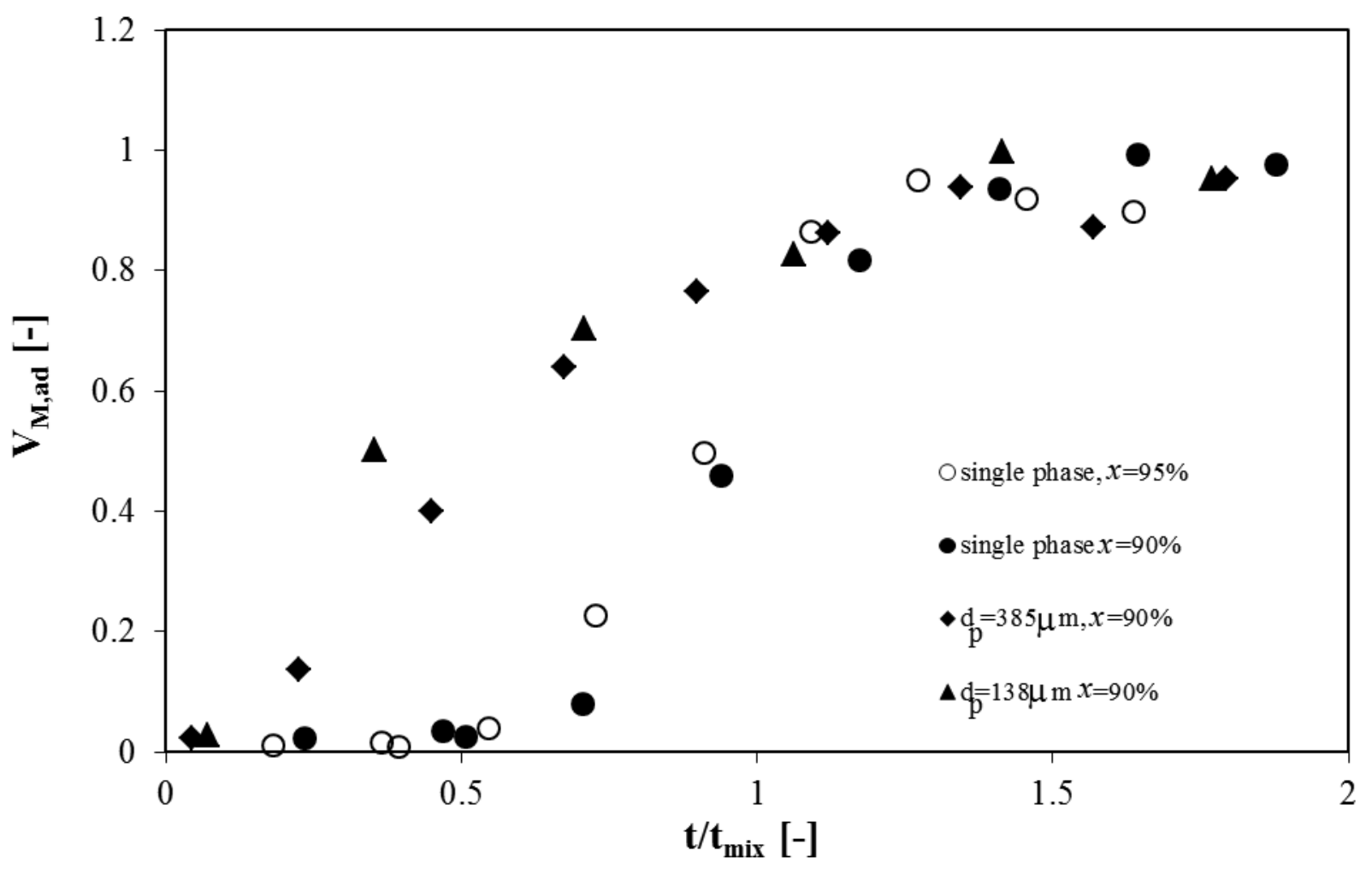

Fig. 16. Time evolution of the dimensionless well mixed volume.

\section{Conclusions}

The liquid homogenization dynamics in stirred suspensions of glass particles at high solid loading have been investigated by a quantitative volume based estimation method for the first time with the use of ERT. The advantages of moving towards whole-field experimental methods applicable to opaque systems are demonstrated. The main conclusions of this work are listed below:

- The conductivity data collected under different conditions (particle size, impeller speed, tracer injection point) have confirmed that the liquid homogenization requires a much longer mixing time with respect to the single-phase systems.

- The estimation of the tracer concentration distribution over four cross-sections of the vessel has highlighted that the tracer addition position has a significant or negligible effect on the liquid homogenization dynamics, depending on the solid size.

- The intensity, the scale and the rate of change of mixing estimated by the volumetric reconstruction of the instantaneous tracer distribution during the homogenization process provide insight into the process dynamics exploiting the detailed data collected by the ERT. 


\section{Acknowledgment}

This work has been carried out by the financial support of the University of Bologna and the Italian Ministry of University and Research (MIUR) under the project SO.FI.A CTN01_00230_450760. Claudio Carletti wishes to express his gratitude to the Graduate School in Chemical engineering (GSCE) of Finland for financial support to his stay at the University of Bologna during his $\mathrm{PhD}$.

\section{Nomenclature}

$\mathrm{A}_{\mathrm{M}} \quad$ well mixed area, $\mathrm{m}^{2}$

C clearance, $\mathrm{m}$

$\mathrm{C}_{\mathrm{i}}$ dimensionless conductivity in the cell $\mathrm{i}$, dimensionless

D impeller diameter, $m$

$\mathrm{d}_{\mathrm{eq}} \quad$ equivalent diameter, $\mathrm{m}$

$d_{p} \quad$ particle volume averaged mean size, $\mu \mathrm{m}$

$\mathrm{H} \quad$ vessel height, $\mathrm{m}$

$\mathrm{H}_{\mathrm{L}} \quad$ liquid height, $\mathrm{m}$

$\mathrm{N} \quad$ impeller speed, $\mathrm{s}^{-1}$

NIS just suspended impeller speed $\mathrm{s}^{-1}$

$\mathrm{T} \quad$ vessel diameter, $\mathrm{m}$

$\mathrm{t}$ time, $\mathrm{s}$

$t_{95}$ mixing time at $95 \%$ homogeneity level, $\mathrm{s}$

$\mathrm{V} \quad$ vessel volume, $\mathrm{m}^{3}$

$\mathrm{V}_{\mathrm{M}} \quad$ well mixed volume, $\mathrm{m}^{3}$

$\mathrm{V}_{\text {Mad }}$ dimensionless well mixed volume, dimensionless

$\mathrm{Z}_{1}, \mathrm{Z}_{2}, \mathrm{Z}_{3}, \mathrm{Z}_{4} \quad$ measurement planes

$\mathrm{X}$ mass ratio of suspended solid to liquid, dimensionless

$x \quad$ degree of homogeneity, dimensionless

\section{Greek letters}

$\bar{\sigma} \quad$ volume mean conductivity, $\mathrm{mS} / \mathrm{cm}$

$\sigma_{\mathrm{i}} \quad$ average conductivity on a plane, $\mathrm{mS} / \mathrm{cm}$

$\sigma_{\mathrm{k}} \quad$ conductivity of a pixel, $\mathrm{mS} / \mathrm{cm}$ 
$\sigma_{1} \quad$ conductivity of continuous phase, $\mathrm{mS} / \mathrm{cm}$

○l liquid density, $\mathrm{kg} / \mathrm{m}^{3}$

$\sigma_{\mathrm{m}} \quad$ conductivity of the slurry, $\mathrm{mS} / \mathrm{cm}$

$\sigma_{\mathrm{s}} \quad$ conductivity of dispersed phase, $\mathrm{mS} / \mathrm{cm}$

$\rho_{\mathrm{s}} \quad$ solid density, $\mathrm{kg} / \mathrm{m}^{3}$

$\chi_{\mathrm{i}} \quad$ normalized local conductivity, dimensionless

\section{References}

Assirelli, M., Bujalski, W., Eaglesham, A., Nienow, A.W. 2002. Study of micromixing in a stirred tank using a Rushton turbine: Comparison of feed positions and other mixing devices. Chem. Eng. Res. Des. 80, 855-863.

Ayranci, I., Machado, M.B., Madej, A.M., Derksen, J.J., Nober, D.S., Kresta, S.M., 2012. Effect of geometry on the mechanisms for off-bottom solids suspension in a stirred tank. Chem. Eng. Sci., 79, 163-176.

Ayranci, I., Kresta, S.M., Derksen, J.J., 2013. Experiments and simulations on bidisperse solids suspension in a mixing tank. Chem. Eng. Technol., 36, 1957-1967.

Babaei, R., Bonakdarpour, B., Ein-Mozaffari, F., 2015. Analysis of gas phase characteristics and mixing performance in an activated sludge bioreactor using electrical resistance tomography, Chem. Eng. J., 279, 874-884.

Balachandar, S., Eaton, J.K., 2010. Turbulent dispersed multiphase flow. Annual Review of Fluid Mechanics 42, 111-133.

Brown D.R., Jones P.N., Middleton J.C., Papadopoulos G., Arik E.B., Chapter 4, Experimental methods, p. 164-170, [in:] Paul, E.L., Atiemo-Obeng, V.A., Kresta, S.M. (Eds.), Handbook of Industrial Mixing, Wiley-Interscience: Hoboken, NJ.

Bujalski, W., Takenaka, K., Paolini, S., Jahoda, M., Paglianti, A., Takahashi, K., Nienow, A.W. and Etchells, A.W. (1999). Suspension and liquid homogenization in high solids concentration stirred chemical reactors. Chem. Eng. Res. Des., 77, 241.

Micheletti, M., Nikiforaki, L., Lee, K.C. and Yianneskis, M. (2003). Particle concentration and mixing characteristics of moderate-to-dense solid-liquid suspensions. Ind. Eng. Chem. Res., 42, 6236-6249. 
Carletti, C., Montante, G., Westerlund, T., Paglianti, A., (2014). Analysis of solid concentration distribution in dense solid-liquid stirred tanks by electrical resistance tomography. Chem. Eng. Sci., 119, 53-64.

Dickin, F., Wang, M., 1996. Electrical resistance tomography for process applications. Meas. Sci. Technol., 7, 247-260.

Dudukovic, M.P. (2002). Opaque multiphase flows: Experiments and modelling. Exp. Therm Fluid Sci., 26, 747-761.

Grenville, R.K., Nienow. A.W. 2004. Blending of Miscible Liquids. Chapter 9 in "Handbook of Industrial Mixing: Science and Practice" (Paul, E.L., Atiemo-Obeng, V.A., Kresta, S.M., Eds), Wiley-Interscience: Hoboken, NJ.

Hamood-ur-Rehman, M., Dahman, Y., Ein-Mozaffari, F., 2012. Investigation of mixing characteristics in a packed-bed external loop airlift bioreactor using tomography images. Chem. Eng. J., 213, 50-61.

Harrison, S., Stevenson, R., Cilliers, J. J. 2012. Assessing solids concentration homogeneity in Rushton-agitated slurry reactors using electrical resistance tomography (ERT). Chem. Eng. Sci., 71, 392-399.

Holden, P. J., Wang, M., Mann, R., Dickin, F. J., Edwards, R. B. 1998. Imaging stirredvessel macromixing using electrical resistance tomography. AIChE J., 44, 780-790.

Hosseini, S., Patel, D., Ein-Mozaffari, F., Mehrvar, M. 2010. Study of solid-liquid mixing in agitated tanks through electrical resistance tomography. Chem. Eng. Sci., 65, 13741384.

Kim, S., Nkaya, A.N., Dyakowski, T., 2006. Measurement of mixing of two miscible liquids in a stirred vessel with electrical resistance tomography. Int. Commun. Heat Mass Transfer, 33, 1088-1095.

Kraume, M., 1992. Mixing times in stirred suspensions. Chem. Eng. Technol., 15, 313-318.

Kukukova, A., Aubin, J., Kresta, S.M., 2009. A new definition of mixing and segregation: Three dimensions of a key process variable. Chem. Eng. Res. Des., 87 (4), pp. 633-647.

Kukuková, A., Noël, B., Kresta, S.M., Aubin, J., 2008. Impact of sampling method and scale on the measurement of mixing and the coefficient of variance, AIChE J., 54, 30683083. 
Mann, R., Stanley, S., Vlaev, D., Wabo, E. 2001. Augmented-reality visualization of fluid mixing in stirred chemical reactors using electrical resistance tomography. J. Electron. Imaging, 10, 620-629.

McKee, S. L., Williams, R. A., Boxman, A., 1995. Development of solid-liquid mixing models using tomographic techniques. Chem. Eng. J., 56, 101-107.

Micheletti, M., Nikiforaki, L., Lee, K.C., Yianneskis, M. 2003. Particle concentration and mixing characteristics of moderate-to-dense solid-liquid suspensions. Ind. Eng. Chem. Res., 42, 6236-6249.

Montante, G., Paglianti, A. 2015. Gas hold-up distribution and mixing time in gas-liquid stirred tanks, Chem. Eng. J., 279, 648-658.

Pakzad, L., Ein-Mozaffari, F., Upreti, S.R., Lohi, A., 2013. Evaluation of the mixing of non-Newtonian biopolymer solutions in the reactors equipped with the coaxial mixers through tomography and CFD. Chem. Eng. J., 215-216, 279-296.

Rodgers, T.L., Cooke, M., Siperstein, F.R., Kowalski, A., 2009. Mixing and dissolution times for a cowles disk agitator in large-scale emulsion preparation. Ind. Eng. Chem. Res., 48, 6859-6868.

Rodgers, T.L., Gangolf, L., Vannier, C., Parriaud, M., Cooke, M., 2011. Mixing times for process vessels with aspect ratios greater than one. Chem. Eng. Sci., 66, 2935-2944.

Sardeshpande, M.V., Sagi, A.R., Juvekar, V.A., Ranade, V.V., 2009. Solid suspension and liquid phase mixing in solid-liquid stirred tanks. Ind. Eng. Chem. Res., 48, 9713-9722.

Sardeshpande, M.V., Kumar, G., Aditya, T., Ranade, V.V., 2016. Mixing studies in unbaffled stirred tank reactor using electrical resistance tomography. Flow Meas. Instrum., 47, 110-121.

Sharifi, M., Young, B. 2013. Electrical resistance tomography (ERT) applications to chemical engineering. Chem. Eng. Res. Des., 91, 1625-1645.

Stanley, S. J., Bolton, G. T. 2008. A review of recent electrical resistance tomography (ERT) applications for wet particulate processing. Part. Part. Syst. Char., 25, 207-215.

Tahvildarian, P., Ng, H., D'Amato, M., Drappel, S., Ein-Mozaffari, F., Upreti, S.R., 2011. Using electrical resistance tomography images to characterize the mixing of micronsized polymeric particles in a slurry reactor. Chem. Eng. J., 172 (1), pp. 517-525. 
Yeoh S.L., Papadakis, G., Yianneskis M. 2005. Determination of mixing time and degree of homogeneity in stirred vessels with large eddy simulation. Chem. Eng. Sci., 60, 2293 2302.

Wang, M., Dorward, A., Vlaev, D., Mann, R. 2000. Measurements of gas-liquid mixing in a stirred vessel using electrical resistance tomography (ERT). Chem. Eng. J., 77, 93-98.

Williams, R. A., Jia, X., McKee, S. L. 1996. Development of slurry mixing models using resistance tomography. Powder Technology, 87, 21-27. 